\title{
¿QUÉ QUIERE DECIR «RACIONAL»? \\ (MULTIUSOS DE ESE TÉRMINO PERSUASIVO)
}

\author{
WHAT DOES “RATIONAL” MEAN? \\ (MULTI-USES OF THAT PERSUASIVE TERM)
}

\author{
Enrique Pedro Haba*
}

\section{RESUMEN}

Este trabajo discrimina entre una multifacética variedad de significados que «racionalidad» recibe mediante distintos usos de este término, principalmente para ámbitos de la llamada Razón práctica. Es puesto así de manifiesto el carácter opcional-voluntarista al elegir entre esos usos (precisos o imprecisos) y se concluye subrayando la connotación emotivo-retórica (lenguaje persuasivo) que ellos suelen llevar aneja. Al final se consigna una amplia bibliografía sobre el tema.

PALABRAS CLAVE: RAZÓN * RACIONAL * RAZONABLE * SEMÁNTICA * LENGUAJE PERSUASIVO

\section{ABSTRACT}

This paper offers a wide array of meanings for «rationality», they are mainly used in order to achieve heterogeneous goals for the so called practical Reason. The choices between those language uses (whether precise or imprecise) are indeed optional, a kind of voluntaristic knowledge; the present study underlines the emotional-rhetorical connotation (persuasive language) that they often carry with them. In addition, an extensive bibliography on the subject is included at the end.

KEYWORDS: REASON * RATIONALITY * REASONABLE * SEMANTICS * PERSUASIVE LANGUAGE 
SUMARIO

A) Pluridimensionalidades del término «racionalidad» ............... 167 (Un repertorio de sus juegos de lenguaje académicos)

I. Definición de «racionalidad»: cuatro grandes tipos ......... 167

II. Campo semántico . . . . . . . 169

III. Subespecies de «racionalidad». 170

IV. Persuasividad de las definiciones al respecto ............. 174

B) Una bibliografía a propósito de «racional»................... 178

$$
* * *
$$

... la racionalidad y la irracionalidad. Pocas palabras se usan en manera tan múltiple y contradictoria como estas dos.

... y así confío en vencer cualquier obstáculo. A quien no concuerde conmigo, le negaré la facultad de comprender lo racional.

Suele darse por entendido ${ }^{1}$ que los pensamientos y conductas de orden racional se caracterizan, como tales, por no responder simplemente a impulsos de la vida emocional (si bien ni aun los de ese orden son independientes del todo con respecto a ella: juicios de valor «categóricos» ${ }^{2}$, variedades de sentimientos, costumbres que responden simplemente a estos últimos). Pero las opiniones divergen, $y$ no poco, en cuanto a precisar de qué o cómo se trata EspecífiCAMENTE en aquellas formas de pensar, para hacer efectiva esta diferencia primaria de grosso modo.

El presente estudio procura responder a tal interrogación. Mas no la indaga bajo el supuesto de que acaso sea cuestión de aprehender algo así como un significado propiamente

1 Las dos citas iniciales pertenecen, respectivamente a Mannheim, 1969, p. 38 y Jhering, 1974, p. 149.

Téngase presente la diferencia, fundamental, entre juicios de valor categóricos y juicios de valor instrumentales: cf. Hempel, 1979, cap. III (esp. núms. 3 y 4: p. 92 y ss.). Véase también: Haba, 2010a, \# 154-155 (p. 213 y ss.); o Haba, 2012, Sec. E.III («Recurso a las ciencias sociales para fundamentar conclusiones normativas»). verdadero para dicho término: tal o cual supuesta definición real ${ }^{3}$ (y suele ser esencialista ${ }^{4}$ ), naturalismo lingüístico ${ }^{5}$. Me importa sobre todo llamar la atención hacia lo contrario: el hecho de que cada locutor, al utilizar esa palabra en calificar comportamientos humanos (sean materiales o unas formas de pensamiento), elige entre sus variadísimas posibilidades semánticas, para que el prestigio de tal término resulte imputado a alguna preferencia especial - suya personal, pero también de otros - acerca de las materias consideradas. Entonces él no puede evitar la opción entre los dos extremos siguientes: ya sea dejar aclarado en forma expresa a cuál o cuáles de esos múltiples sentidos entiende referirse específicamente ahí, $y$ haciéndolo con precisión suficiente de no dejar en confusión el suyo propio con otros de aquellos; o bien, omitir tal precisión, en cuyo caso buena parte del fárrago de polisemias $y$ vaguedades $y$ contradicciones que esa palabra conlleva ${ }^{6}$ (cuando no es aclarada) pasa a formar parte también de su propia exposición. Esto último constituye lo más habitual.

En efecto, no poco común es encontrarse con esta segunda salida, sin excluir exquisitas elucidaciones académicas en donde «racional» $y$ otros términos muy emparentados se emplean omitiendo simplemente tales aclaraciones ${ }^{7}$,

3 Cf. Robinson, 1954, cap. vi (p. 46 y ss.: «Real definition»).

$4 \quad$ Cf.: Albert, 1987, § 13 (p. 66 y ss.: «El esencialismo y la búsqueda de aclaraciones últimas»); Robinson, 1954, cap. VI (esp. §§ 2 y 7); Haba, 2007, § 2 (p. 496 y ss.: «Rasgos fundamentales de la orientación esencialista (sus principales tesis carecen de sustentación empírica)»; Haba, 2012, Sec. D.II.4 («Esencialismo») [esta obra trae también un examen mucho más circunstanciado en el t. III, su Tema 8: «Esencialismo y "naturalezas jurídicas" (Caminos en el "cielo" para la doctrina jurídica)»].

5 Cf. Haba, 2012, Sec. B.I.1 («Carácter convencional ("arbitrariedad") de toda expresión lingüística»; esp. a la altura de su n. 5).

6 Cf. Haba, 2012, Sec. C.I («Fundamentaciones e intersubjetividad. Lo racional y lo razonable»).

$7 \quad$ Tan fuerte es tal inclinación del pensamiento al esencialismo, que no dejamos de hallarla asumida (espontáneamente) hasta en exámenes de finos conocedores de la filosofía analítica. Por ejemplo, es el caso de un conocedor experto en 
como si el sentido de ellos fuere bastante obvio. Semejantes faltas de claridad básicas hacen que, de hecho, se aproveche simplemente la carga emotiva encomiástica que las palabras «razón» o «racional» portan consigo (o recurrir al amparo de su bien condescendiente hijastro: lo «razonable»), sean cuales fueren sus variados referentes efectivos en las conductas lingüísticas abarcadas así. El siguiente «diccionario» $[\mathrm{A}]^{8}$ ofrece elementos de juicio al respecto, va dirigido a tratar de evitar la tentación de emplear in-distintamente los susodichos términos.

[Naturalmente, nadie pretenderá que para cada utilización de estas palabras, ni aun tratándose de estudios que se interesen en examinar aspectos decisivos de sus usos considerados ahí, entonces sea cuestión de que el autor pase revista a todas o la mayoría de las variantes de sentido que al respecto serán desglosadas acá. No obstante, aunque por cierto él no necesita estar enterado de tanta multiplicidad (no es común que ni aun la sospeche), de todos modos resulta indispensable, si pretende formular sus ideas con bastante precisión, que en todo caso deje bien en claro a cuál sentido en especial entiende referirse. Al menos corresponde aclarar si se trata ahí, para él, de una «racionalidad» instrumental (Weber) vale decir, distinguiendo bien a qué fines específicos (i.e., cuyos elementos de composición sean diferenciables de modo netamente intersubjetivo) han de estar ordenados los medios empíricos para implementarla- o si , en cambio, entiende referirse a alguna otra suerte de «racionalidad»y en este últimoso: ¿cuál?. Por lo general, tales aclaraciones brillan por su ausencia].

Wittgenstein, el profesor Bouveresse, al examinar qué quiere decir «raison»; sus análisis sobre ello dan por presupuesto, implícitamente, que grandes discrepancias al respecto entre importantes pensadores se refieren a algo así como UN mismo objeto de referencia, la Razón [cf..: Bouveresse, 2011 y 2012; Tiercelin, 2014].

8 Su contenido proviene básicamente del texto que escribí para la entrada «Rationalité», en Arnaud, 1988, pp. 337-340. El presente artículo es una versión sensiblemente reelaborada (corregida, ampliada y actualizada) de dicho trabajo.
A) PLURIDIMENSIONALIDADES DEL TÉRMINO «RACIONALIDAD» (UN REPERTORIO DE SUS JUEGOS DE LENGUAJE ACADÉMICOS)

One might say of such words that they serve as pegs: it's marvellous what a lot of things you can put on them.

A mi juicio, constituye un auténtico obstáculo en la discusión sobre racionalidad, el hecho de que la palabra «racional» sea a menudo - aunque no siempre - entendida ante todo como un término valorativo; de modo tal que algunos teóricos tratan de invertir en su concepto de racionalidad todo aquello que consideran bueno, mientras otros temen llamar «racional» acaso a las conductas de delincuentes, porque estas no armonizan con nuestras exigencias morales ${ }^{9}$.

I. DEFINICIÓN DE «RACIONALIDAD»: CUATRO GRANDES TIPOS

1. RACIONALIDAD en sentido latísimo. Empleando el término de la manera más genérica $y$ sin precisiones, entonces a un pensamiento o una acción o un estado de cosas, o a varios de ellos en conjunto, sean estos cuales fueren y producidos cómo fuere, se les adjudica el calificativo «racional» para enfatizar que tal es justamente la manera correcta de ser llevado a cabo aquello, a juicio de quienes consideran alabable eso mismo.

2. RACIONALIDAD en sentido amplio. Son modelos delineadamente estructurados -al menos en apariencia- de quedar en orden (o en todo caso ello es «visto» como tal) los referentes encarados, ya sea por cuanto respecta a ideas (formas de pensamiento) o para maneras de actuar (conductas $y$ procedimientos, individuales 0 colectivos) o aun en cuanto a la composición de objetos dados (naturaleza, mundo social). Con ello se entiende implicado, también, que necesariamente esto mismo

$9 \quad$ Estas dos citas corresponden, respectivamente a Waismann, 1951, p. 136 y Albert, 1994, p. 255 (trad. E.P.H.). 
encarna o resulta lo apto para promover ciertos tipos de resultados valorados como de especial relevancia positiva; y de ahí que eso sea considerado como propio de, o se proclama como deseable o hasta obligatorio para, las actuaciones de las personas, en tales o cuales respectos. Mas esos «órdenes» son laxos o hasta muy laxos; tampoco es extraño que unos resulten antinómicos con respecto a otros, o que el mismo orden reciba interpretaciones contradictorias entre sí, tanto en sus propios contenidos teoréticos como por cuanto hace a sus aplicaciones prácticas ${ }^{10}$.

Caracterización un poco más explicitada. Orden no-arbitrario y considerado exitoso, ya sea de unas ideas (formas de pensamiento) o para maneras de actuar (conductas y procedimientos, individuales o colectivos) o en cuanto a cierto conjunto de «cosas» (o unos aspectos de estas) en sí mismas (naturaleza, mundo social), y que de tal manera conforman algún modelo considerado deseable; ello visto en nivel sincrónico (determinadas estructuras estables, o tenidas por tales) o de modo dinámico (métodos para procedimientos intelectuales o materiales, o concepciones teleológicas sobre procesos de la Historia). Estas tres esferas de racionalidad — pensamiento, actividades, objetos-«cosas»- pueden incluso corresponderse entre sí, más o menos, para tales o cuales rubros; ya sea porque sería el propio espíritu humano quien establece (o contribuye a delinear) los esquemas o relaciones en que consiste el orden respectivo, o bien porque en todo caso sería posible constatar la existencia de dichas relaciones y actuar en consecuencia. Por lo demás, casi siempre se da por entendido que todo orden llamado «racional» encarna valores positivos, para guiar el pensamiento y la conducta de las personas, en tales o cuales respectos. Los «órdenes» así señalados son múltiples; aparecen concebidos en formas muy diversas, no pocas veces contradictorias unas con otras, tanto en sus contenidos teoréticos como por cuanto hace a sus aplicaciones prácticas. [No se me escapa que semejante descripción puede lucir demasiado extensa para constituir una «definición» propiamente dicha, y hasta resultar en cierto modo artificiosa por ese detallismo (de hecho, los locutores de la palabra «racional» no tienen in mente tal minuciosidad). Mas entiendo que en todo caso ello permite trazar un marco general de ubicación discursiva para deslindar la enorme mayoría de los usos de dicho término; marco dentro del cual corresponderá especificar luego, para cada caso o tipo de
3. RACIONALIDAD en sentido estricto. En general: modelos de razonamiento netamente intersubjetivos (al menos entre los conocedores de las disciplinas respectivas), en lógica formal o los acreditados en ciencias de la naturaleza. Y para las ciencias sociales, tal sentido señala la adaptación técnica de medios empíricos necesarios o convenientes para alcanzar de modo efectivo un fin dado, haciendo abstracción de los juicios de valor sobre esos medios en sí mismos o sobre ese fin: racionalidad «formal», «razón instrumental».

4. RACIONALIDAD más especialmente, en cuanto al derecho. Se corresponde sobre todo con el tipo de sentidos 2 , incluido señaladamente su componente fundamental de valoración positiva, en cuanto ello es aplicado para calificar las reglas jurídicas por sí mismas o los discursos de locutores especializados en ese dominio (sus doctrinas reconocidas $y$ en general las argumentaciones jurídicas profesionales) o inclusive para caracterizar renglones de la vida misma del complejo tejido de funciones sociales correspondientes (creación y aplicación del derecho).

Etimología.- Del latín rationalitas, facultad de ejercer la ratio, cálculo, apreciación, cuenta de las operaciones que se hacen. De donde resulta: evaluación, facultad de razonar, juicio, inteligencia, explicación, argumentación, razonamiento, teorías.

Traducción.- Al.: Rationalität; y, en sentido amplio, Vernünftigkeit (eventualmente Vernunftmässigkeit ${ }^{11}$ o vernunftmässig). Ingl.: Rationality. Fr.: Rationalité. It.: Rationlitá. Port.: Racionalidade.

$$
* * *
$$

casos en consideración, las especies y subespecies de «racionalidad», respectivamente más específicas (infra: $\$ \S$ II y III), de que se trate ahí]. 


\section{CAMPO SEMÁNTICO}

1. La palabra «racionalidad» ofrece mucho del multifacético contenido que caracteriza al término base del cual ella proviene, la idea de ratio/razón ${ }^{12}$. Lo propio ocurre con vocablos como «racional»y «razonable», cuyos usos en buena medida se corresponden, o en todo caso están estrechamente emparentados, con sentidos que igualmente recibe aquella primera.

Asimismo, las relaciones entre estos últimos dos términos se presentan de maneras muy variadas. No suele diferenciarse bien entre ambos, son empleados prácticamente como sinónimos; salvo por parte de unas orientaciones teoréticas que utilizan estas palabras para subrayar justamente diferencias fundamentales entre los respectivos modos de pensamiento, ya sea señalando lo «razonable» como una especie particular dentro de lo racional in genere (supra § I: acepción 1) o como una modalidad de pensamiento aparte frente a dicho género.

Las orientaciones que sustentan estos dos últimos enfoques [i.e., las que acabo de señalar diciendo: «salvo»... ] —Toulmin,1958; Perelman, 1979; más continuadores actualesabogan por tal senda aparte como la alternativa adecuada para la Razón práctica. Pero también hay quienes consideran que, si bien la diferencia por cierto existe y es muy decisiva, las apologías de lo «razonable» suelen consistir sobre todo en maneras de disimular el «ir-racionalismo» que caracteriza a esas maneras de razonar: sus fundamentales indeterminaciones, sus «celadas» lingüísticas habituales, en general, el voluntarismo que preside esos razonamientos que aparecen cohonestados asi ${ }^{13}$.

12 Cf. Lalande, 1968, voz «Raison». Además: Anacker, 1974; Blanché, 1973, cap. V; Bouveresse, 2011 y 2012; Correas, 2009; Granger, 1972; Tiercelin, 2014; Toumin, 1979.

13 Cf. Haba, 2012, Secs. C.I (§§ 5-«Lo "razonable"», 6-«Múltiples modalidades de "racionalidad", carácter persuasivo de esta palabra», 11-«Conclusión: ¿lo racional o lo "razonable"?») y F.5 («Contraposición a los enfoques "razonabilistas"»).
Todos esos términos son polisémicos; $y$ se suelen emplear persuasivamente, al menos cuando son usados para caracterizar las argumentaciones en campos de la llamada Razón práctica ${ }^{14}$. Lalande define Racionalidad como «carácter de lo que es racional, en particular en el sentido laudatorio de la palabra razón»; a su vez, señala que Racional es «lo que pertenece a la razón, o es conforme a esta... En particular, lo que es lógico y conforme a un buen método»; y Razonable es «Quien posee la razón... Quien piensa o actúa de una manera que no se puede censurar». Por lo demás, hay señaladas relaciones entre todas estas formas y los diversos aspectos del razonamiento ${ }^{15}$.

De esos vocablos deriva el término racionalismo, al caracterizar a tendencias del pensamiento filosófico o el científico. Tal calificación aparece reivindicada en sentido altamente aprobatorio por parte de unas escuelas de pensamiento - cf. Bachelard, Albert (con base en Popper)—, mas no así por ciertas otras. Estas últimas - hegelianos $y$ «dialécticos» en general, heideggerianos $y$ «hermenéuticos» en general, «postmodernistas», etc. - entienden que los «positivistas» (así llaman, bastante indiscriminadamente, a escuelas como aquellas primeras) se aferran a visiones esencialmente «empobrecedoras», — «menguadas», «reduccionistas», «fijistas», falsadoramente «objetivizantes», etc. ${ }^{16-}$ acerca de las realidades humanas.

2. De los tipos de acepciones que Lalande indica para la voz Raison (razón) — cinco (A-E) «en cuanto facultad»y tres $(\mathrm{F}-\mathrm{H})$

14 Cf. Haba, 2012, Sec. C.I.7 («Múltiples modalidades de "racionalidad", carácter persuasivo de esta palabra»). De modo más general, sobre los usos persuasivos de la «razón», vid.: Mosterín, 1976; Perelman, 1963 (esp. cap. I: «De la justice»); Rother, 1972; Schopenhauer, 2004. Por cuanto concierne específicamente a discursos de las ciencias, sobre todo las de lo social, véase: Debray. 1963; Dubos, 1967; Salas, 2011.

15 Para detallados exámenes acerca de esas relaciones: Blanché, 1973 y Granger, 2004.

16 P. ej., véase los puntos de vista al respecto que sostienen aproximaciones como las pregonadas por: Bloch, 1983; Gadaner, 1977; Habermas, 1973 y Marcuse, 1972. 
«en cuanto objeto de conocimiento», al término racionalidad han pasado sobre todo tres de ellas en los usos que este rubro lingüístico exhibe en la actual teoría de las ciencias sociales: «B. Facultad de "juzgar bien", es decir, de discernir el bien y el mal, lo verdadero y lo falso» (véase, p. ej., el sentido y la función que Habermas asigna a la «fundamentación discursiva»: Diskurs ${ }^{17}$ ); «G. Principio de explicación, en sentido teórico; razón de ser: aquello que da cuenta de un efecto» (p. ej., la racionalidad con arreglo a fines -Weber-); «H. en sentido normativo, causa o motivo legítimo, justificación» (p. ej., las argumentaciones ${ }^{18}$ ).

3. En la discusión epistemológica sobre la metodología de dichas ciencias, el término «racionalidad» toma ubicación clave desde las dos primeras décadas del siglo pasado, empleado por Weber para calificar - si la palabra es utilizada en sentido propio (estrecho, estricto) - una modalidad específica de conductas: las del tipo que él llama zweckrational, la racionalidad de los medios con respecto a fines aceptados. Este tipo, por su base científica, se diferencia netamente frente a otras tres clases de conducta: la racionalidad con arreglo a valores (wertrational), la afectiva o emocional, la tradicional. A partir de entonces quedan bien diferenciadas las dos grandes categorías de racionalidad: la formal (de medios, empírico-instrumental, científico-analítica, avalorativa) y la material (sustancial, valorativa, que se predica de ciertos fines qua valores en sí mismos, mediante variados tipos de pensamientos: «dialécticos», «hermenéuticos», religiosos, etc. — cada uno de esos tipos bajo, a su vez, múltiples modalidades-).

17 Cf. Habermas, 1985 y 1989.

18 Así en cuanto, por ejemplo, a consideraciones sobre legalidad o legitimidad de justificaciones invocadas a título de «Razón Jurídica»: cf. Carrión Wam, 1994b.
Hasta nuestros días se prolonga la discusión sobre si —como entendía Weber, y siguen sosteniendo las distintas tendencias de orientación analítica- únicamente la racionalidad formal es susceptible de hallar sostén en el plano científico (cf. la polémica de Albert, 1973a, contra Habermas, 1973). Eso sí, aun dicha racionalidad puede ser delineada de distintas maneras, según unas $\mathrm{u}$ otras especies de ella ${ }^{19}$. Por el otro lado, asimismo hay diferentes concepciones de la racionalidad material, las discrepancias al respecto pueden ser radicales: considérese, p. ej., la discusión entre partidarios de la «hermenéutica» ${ }^{20}$; en cuanto a la «dialéctica», véase la querella entre el marxismo de tipo soviético y la Escuela de Francfort ${ }^{21}$, o aun las diferencias de lo que es la «dialéctica crítica» en Sartre.

\section{SUBESPECIES DE «RACIONALIDAD»}

[Nota. - Aquí ni es dable presentar sino de la manera más sucinta cada una de las variantes que serán señaladas. Mas en las notas subpaginales se indican, respectivamente, sitios donde hay explicitaciones propiamente dichas sobre cada una de aquellas; el lector queda así advertido no solo sobre la existencia misma de tanta suerte de variantes (propósito principal del presente trabajo), sino también en condiciones de obtener información en detalle sobre cualquiera de las mencionadas, señaladamente en cuanto a las que logren despertar su interés en especial, para lo cual encuentra identificadas aquí unas fuentes bibliográficas correspondientes].

1. Sea como sea, una «racionalidad» puede localizarse en diversos planos, según el ángulo hacia el cual se dirija la atención. Las clases de criterios tomados en cuenta para dilucidar si ella está o no está presente difieren en función del plano considerado, pero también de acuerdo con las bases teoréticas de que se parta al abordarlo. Cabe distinguir, ante todo, cinco grandes

\footnotetext{
$19 \quad$ P. ej.: Priester, 1970, recoge 17 definiciones (pp. 461 y ss.); vid. también Schutz, 1974, § V (p. 78 y ss.).

20 Cf. Apel/Gadamer/Habermas, 1971.

21 Cf.: Heiseler et ál., 1970; Marcuse, 1969.
} 
pares de alternativas [en cada grupo, sus dos grandes tipos de opciones se presentan separándolos entre sí mediante un guión largo:-]:

A) $\mathrm{A}_{1}$. Racionalidad oвjetiva: del mundo, de sus «cosas». - $\mathrm{A}_{2}$ Racionalidad SUBJETIVA: del sujeto cuando se aboca a aprehender o manejar esas «cosas».

B) $\mathrm{B}_{1}$. Racionalidad TEORÉTICA, de creencias, del discurso: razonamientos, lógica (formal o material), argumentación, métodos de conocimiento. $-\mathrm{B}_{2}$. Racionalidad PRÁCTICA, de la conducta, acciones: actividad cotidiana, técnicas de intervención científica, praxis política, etcétera. Vale decir, se trata de las diferencias y las relaciones entre: creencia $\left(B_{1}\right)$ racional $y$ acción $\left(\mathrm{B}_{2}\right)$ racional ${ }^{22}$.

C) $\quad \mathrm{C}_{1}$. Racionalidad DESCRIPTIVA: racionalidad «como concepto explicativo» científico-empírico [Hempel]; racionalidad de «sistemas» sociales (parsoniana [Parsons, 1999], luhmanniana [Habermas-Luhmann, 1971; Luhmann, $1973]^{23}$ u otras) ${ }^{24}$; racionalidad instrumental (Zweckrationalität: Weber y continuadores ${ }^{25}$ ) en general $y$ en particular para las tomas de decisión ${ }^{26}$; racionalidad

22 Cf. Gibson, 1974, cap. XIV («El supuesto de la racionalidad»).

23 Con respecto a Luhmann, críticamente: Haba, 2013, § 2 (allí p. 519 in fine y ss., «La vertebral falta de referentes empíricos netos - bien diferenciables como tales - en los discursos del tipo "sistémico" luhmanniano»).

24 Para la crítica en general sobre el uso del término «sistema» en las ciencias sociales, véase Haba, 2010b, cap. II (esp. \$§ 4 y 7 y Apéndice c). Un poco más breve en Haba, 2012, Sec. E.I.1 («La ilusión de venir a detectar unos "sistemas" (conformación muy heterogénea, contradictoria y variable de las conductas humanas y de los discursos correspondientes)»). La presentación más sintética de esas ideas se encuentra en Haba, 2000, p. 574 y ss.

Cf. Haba, 2010a, múms. 152-157 (p. 205 y ss.); y véase Löwith, 1960, esp. p. 19 y ss. («II. La "racionalidad" como la expresión problemática del mundo moderno» [trad. E.P.H.]).

Cf.: Arrow, 1963; Kutschera, 1973; Priester, 1970; Schlinck, 1972 y Stegmüller, 1973. axiológico-científica ${ }^{27}$ y en especial para la fundamentación moral [Kraft, 1961]. - $\mathrm{C}_{2}$. Racionalidad intrínsecamente VALORANTE: Wertrationalität (racionalidad con arreglo a valores [Weber, 1964]), racionalidad «como concepto normativocrítico» [Horkheimer, 1973], racionalidad crítico-social o política [Habermas, 1971], racionalidad moral en las procedimientos de decisión política [Höffe], etcétera.

D) $\mathrm{D}_{1}$. Racionalidad SINCRÓNICA, estática: un orden de cosas dado. $-\mathrm{D}_{2}$. Racionalidad DIACRÓNICA: cambios en las formaciones sociales (Dialéctica de la Historia ${ }^{28}$ ), evolución de las sociedades, etc.; desarrollo del conocimiento humano (la cuestión de su progreso y las «revoluciones científicas $»^{29}$ ); etcétera.

E) $\mathrm{E}_{1}$. Racionalidad en sentido ESTRICTO, «dura»: intersubjetividad neta $\left(«\right.$ fuerte» $\left.{ }^{30}\right)$; es la dominante en lógica formal y las ciencias de la naturaleza, $y$ en decisiones normativas ceñidas a las respectivas condiciones empíricocientíficas de razón instrumental. $-\mathrm{E}_{2}$. Racionalidades en sentido AMPLIO, «blanda»: discusiones sobre lo «razonable» («prudencia» aristotélica ${ }^{31}$; pensamiento «dialógico», según M. Buber -«dialógica vital»-y otros [Schrey, 1970], argumentación «dialógica»/«no-monotonía» [Piacenza, 1998], etc.); sus respuestas tienen intersubjetividad vacilante 0

27 Cf.: Brecht, 1963, cap. III («Teoría del relativismo axiológico científico (alternativismo axiológico)»); Hempel, 1979, § III (esp. §§ 3-7: p. 92 y ss.); Kraft, 1951.

28 Cf.: Bloch, 1983, § 13; Lukács, 1976; Marcuse, 1971.

29 Cf.: Lakatos/Musgrave, 1975; Toulmin, 1977.

30 Vid. Haba, 2012, Sec. C.I., §§ 3 («Racionalidad (en sentido estricto) como razonamiento intersubjetivo») y 4 («Racionalidad intersubjetiva como forma rigurosa de intersubjetividad»). Véase también infra, n. 32

31 Cf.: Aubenque, 1963; Haba, 1977; Haba, 2012, Sec. C.I (esp. §§ 6-«Lo "razonable” y 11-«Conclusión: ¿lo racional o lo razonable»). 
dividida («débil»32), como suele suceder en las controversias jurídicas, las de política, las de ética, etcétera. [En esta esfera suelen invocarse múltiples suertes de fórmulas vacías ${ }^{33}$. Por cuanto hace en particular para el pensamiento llamado «razonable», se lo presenta basado en categorías de pensamiento cuyos contenidos específicos acomodables a los gustos de tirios y troyanos: así las calificaciones de «universalidad», «coherencia», «consistencia», pretensión de aprehender lo «correcto», etc. ${ }^{34}$ ].

F) Y, en su caso, caben aun sentidos mas peculiares: p. ej., los números «racionales».

Las alternativas A-E no son excluyentes; pueden complementarse entre sí las de un mismo plano, como también existen entrecruzamientos $y$ caben distintas combinaciones entre dos o más planos. Pero también se hacen presente contradicciones, ya sea principales (agudas) o secundarias (más bien leves), entre unas $y$ otras de esas posibilidades.

$$
* * *
$$

2. Por lo demás, hay una serie de subespecies de racionalidad que, aunque de una $\mathrm{u}$ otra manera se inscriben en los planos ya señalados, difieren entre ellas porque respectivamente adoptan tales o cuales ángulos de enfoque específicos. Corresponde distinguir, por ejemplo, entre los siguientes pares de alternativas [en cada grupo, sus dos grandes tipos

32 Para la diferencia entre intersubjetividad «fuerte» e intersubjetividad «débil»: Haba, 2012, Sec. C.I., $\S 4$ («Racionalidad científica como forma rigurosa de intersubjetividad (intersubjetividad "fuerte")» y 6 («Lo "razonable" (intersubjetividad "débil", "arte”...)»); e ibíd.., Sec. C.II.3 («Especies de métodos», esp. su punto «ii) métodos científicos: a) propiamente dichos (sentido estricto), b) en sentido amplio»).

Véase infra: n. 66.

34 La manipulabilidad discursiva de estas etiquetas es puesta netamente de manifiesto, sometiéndolas a examen una por una, en: Haba, 2018. de opciones se presentan separándolas entre sí mediante un guión largo: - ]:

a) $\quad a_{1}$. Racionalidad ATomística: de un acto aisladamente considerado, o de unos pocos actos. - $\mathrm{a}_{2}$. Racionalidad de actos considerados desde perspectivas GLOBALES: planes de vida, «sistemas» sociales, etc.; ello se corresponde, en líneas generales, con la distinción entre «racionalidad instrumental» $y$ «racionalidad inclusiva» ${ }^{35}$.

b) $\quad b_{1}$. Racionalidad de InDividuos: acciones de personas, cuando la conducta en cuestión es imputada a cada una de esas personas respectivamente (su propia «culpa», su inteligencia o no, etc. $)^{36}$. $\mathrm{b}_{2}$. Racionalidad de sujetos colectivos: nación, clase, raza, religión, instituciones, etc. ${ }^{37}$.

c) $\mathrm{c}_{1}$. Racionalidad EXPRESA: métodos, discursos, argumentaciones, etc. $-\mathrm{c}_{2}$. Racionalidad LATENTE, subyacente: de estructuras sociales o psicológicas, «sentido» de «sistemas» sociales (Parsons, Luhmann), Razón de la Historia (Hegel, tal vez Marx) o el «sentido» imputado a esta misma, teodiceas.

d) $d_{1}$. Racionalidad NOMOLÓGICA: referida a leyes empíricas (del todo generales para una esfera o al menos regularidades estadísticas), sean de la naturaleza o de conductas sociales. $-\mathrm{d}_{2}$. Racionalidad del comportamiento ajustado a NORMAS: reglas jurídicas, morales, etc. [cf. Gottlieb, 1968].

e) $e_{1}$. Racionalidad Demostrativa: teoría de la decisión-elección racional

$35 \quad$ Etzioni, 1980: cap. 11.

36 Véase Löwith, 1960, p 30 y ss. («Die Rationalität als Bedingung der freien Selbstverantwortung des Einzelnen inmitten allgemeiner Hörigkeit» —La racionalidad como condición de la responsabilidad propia del individuo en medio de la obediencia general一).

37 Cf. Olson, 1992: esp. § II.C («Estímulos sociales y acción racional»). 
(subtipos básicos ${ }^{38}$ : racionalidad paramétrica y racionalidad estratégica-teoría de los juegos — calzan ahí, entre otras modalidades, específicamente la lógica deóntica y la teoría lógico-formal de la decisión ${ }^{39}-$ ); modelos deductivo-nomológicos y estadísticos, en la explicación científica. He ahí la «razón constructora de máquinas $\left.{ }^{40}\right)$. $-\mathrm{e}_{2}$. Racionalidad NO-DEMOSTRATIVA: probabilidad inductiva, «racionalismo crítico» (Popper, Albert, etc.), plausibilidad de lo «razonable» (su «logos», dice Recaséns Siches), argumentaciones ${ }^{41}$, «lógica viva» (según Vaz Ferreira), etcétera ${ }^{42}$.

f) $\mathrm{f}_{1}$. Racionalidad TECNOLÓGICA («Todo lo real es racional»): «razón instrumental» ${ }^{43}$, «razón planificadora» ${ }^{44}$, derecho como tecnología social ${ }^{45}$ (inclusive la tendencia más específicamente tecnocrática: «Análisis Económico del Derecho» $\left.{ }^{46}\right)$, etc. $-\mathrm{f}_{2}$. Racionalidades

38 Para características básicas al respecto y la controversia teorética acerca de ellas, cf.: Bermúdez, 2009; Coleman, 1990; Elster/Hilland, 1986; Elster, 1990; Paramio, 2000 y 2005; Pizzorno, 1989; Scheffrin, 1985.

Cf.: Alchourrón/Bulygin, 1975; Kilian, 1974; Kutschera, 1973; Schlink, 1972; Stegmüller, 1973; Crítica: Dewey, 1924; Haba, 1996a; Horn, 1962.

Granger, 1972, esp. cap. IV.V («Razón y máquinas»).

Véase: Alexy, 1988 y 1989; Atienza, 2013; Blanché, 1973 (cap. xIv); Gómez Giraldo, 2003; Haba, 2014; Naess, 1975; Perelman, 1979; Perelman/OlbrechtsTyteca, 1989; Piacenza, 1988; Sarlo, 1994; Salas, 2017; Struck, 1977; Toulmin, 1958.

Además de los trabajos señalados en la n. anterior, para apreciar múltiples variantes al respecto cabe considerar también los estudios siguientes (entre muchos otros): Arnswald/Schütt, 2011; Horak, 1969; Kopperschmidt, 1978 y 1980; Perelman, 1963; Polya, 1966: Recaséns Siches, 1971; Rother, 1962; Schopenhauer, 2005.

43 Véase los sitios indicados supra: n. 2. Crítica: Horkheimer, 1973; Marcuse, 1972.

Cf. Tenbruck, 1972.

45 Cf.: Albert, 1978 y 2007; Haba, 2015 (cap. viII) o 2013.
Cf.: González Amuchástegui, 1994; Haba, 2016, núms 320 a (p. 330 y s.: «Observaciones críticas
ÉTICO-POLÍTICA O CRÍTICO-EMANCIPADORA («Todo lo racional es real»): «dialéctica negativa» según Adorno ${ }^{47}$ y Marcuse $^{48}$, papel transformador de las «utopías» según Bloch ${ }^{49}$, «teoría de la sociedad» (estilo Habermas) en vez de «tecnología social» (estilo Luhmann $)^{50}, y$ demás.

g) $g_{1}$. Racionalidad científica (en especial para las ciencias sociales ${ }^{51}$ ), en distintas versiones: analíticas, sistémicas, etc. [Bunge distingue, pero sólo como pasos no-independientes en el seno del sistema científico «global» de racionalidades, siete conceptos o tipos de ellas: conceptual, lógica, metodológica, gnoseológica, ontológica, evaluativa, práctica ${ }^{52}$.] $-\mathrm{g}_{2}$. Racionalidad EXTRA-CIENTÍFICA: conceptos y reglas básicas en cada creencia religiosa ${ }^{53}$ $y$ en general las racionalizaciones de cada mitología social ${ }^{54}$, tradiciones (Burke $y$ en general el pensamiento social conservador, etc.), «razones» de los sentimientos ( $\ll$ El corazón tiene sus razones...», Pascal), inteligencia «emocional», fundamentalismos en general (puntos de vistas absolutistas: de raza, de religión, de nacionalismo, de «clase», de «género», etc.), y demás.

sobre la corriente "Análisis crítico del Derecho"») y 334 (p. 367 y ss.: «"Análisis económico del Derecho": otra moderna novela racionalista»).

47 Cf.: Adorno, 1975; Jay, 1974.

$48 \quad$ Cf.: Marcuse, 1969 (§ 7) y 1972.

49 Cf.: Bloch, 1983, § 25; Gimbernat, 1983. Crítica: Albert, 1973b, § 26 («La esperanza de la catástrofe: escatología política y política utópica»).

50 Cf. Habermas/Luhmann, 1971.

51 Cf.: Albert, 1973b (cap. viI: «El problema de una política racional) y 1978; Gibson, 1974 y Topítsch, 1965.

52 Cf. Bunge, 1985, p. 14.

53 Al considerar esto último como una cuestión epistemológica, corresponde examinar los principales argumentos de «razón» contrapuestos al respecto: cf. Bouveresse, 2011.

54 Cf. Toppitsch, 1971 y 1988 (esp. p. 124 y ss.: «Mythos als Philosophie» —Mitos como filosofía- ). 
h) $h_{1}$. Racionalidad METódica: procedimientos intersubjetivos científicamente acreditados ${ }^{55}$. - $\mathrm{h}_{2}$. Racionalidad A-METÓDICA: «conocimiento personal», según Polanyi; «teoría anarquista del conocimiento», según Feyerabend, 1981; tópica», según Viehweg ${ }^{56}$; «nueva retórica», según Perelman; «dialéctica aristotélica», según Villey; dialéctica hegeliana $y$ la marxista ${ }^{57}$; conocimiento «hermenéutico», según Gadamer, Apel, Ricoeur $y$ otros $^{58}$; etcétera.

i) Y muchas alternativas más: «Razón» (Vernunft) frente a «entendimiento»(Verstand), según Hegel ${ }^{59}$; «razón especulativa» según Whithehead, 1985; etcétera.

Las dos opciones indicadas en el seno de cada uno de los pares (a-i) suelen comportarse como mutuamente excluyentes. Eso no quita que, también en cuanto a estos, se den combinaciones o identificaciones entre miembros de distintos pares: por ejemplo, así como armoniza la racionalidad nomológica con la racionalidad metódica, la racionalidad «negativa» armoniza antes bien con unas racionalidades ametódicas. Por lo demás, quedó señalado que a su vez cada subespecie de racionalidad admite variantes, a veces bastante distintas.

3. Para el derecho, las diferentes posibilidades de racionalidad se pueden traducir (jo no!), unas u otras ${ }^{60}$, en conductas de

$55 \quad$ Cf. Haba, 2012, Sec. C.I.4 («Racionalidad científica como forma rigurosa de intersubjetividad»).

Cf. Viehweg, 1987.Véase también los exámenes siguientes: Kriele, 1977, cap. V; Otte. 1970; Struck, 1971. Cf.: Bloch, 1983 (esp. §§ 9, 19 y 25); Marcuse, 1971. Crítica: Haba, 1978; más breve en Haba, 1990, Apéndice 4.

60 Véase. (entre otros sitios): Archives de Philosophie du Droit, 1978; Arnaud, 1981; Esser, 1972; Ferrajoli, 1998 (y vid. Salas, 2012); Gómez Giraldo, 2003; dos niveles: $\alpha$ ) el discurso de sus locutores especializados - jueces, abogados, profesores en la Facultades de Derecho, etc. - ; $\beta$ ) la «vida» misma de esa compleja red de funciones sociales - creación de normas jurídicas efectivas y aplicaciones prácticas de estas- que son identificadas mediante aquel término. Por lo demás, aun el primero de estos dos niveles incluye toda suerte de antinomias conceptuales $^{61}$, las cuales contribuyen a moldear cómo se presentan las múltiples contradicciones interpretativas que se dan entre los discursos de esos mismos locutores.

\section{PERSUASIVIDAD DE LAS DEFINICIONES AL RESPECTO}

1. Atento a la amplia variedad de sus tipos y subtipos, sería en vano procurar una definición genérica de racionalidad que los englobe a todos, si esta ha de tener precisión. En el mejor de los casos, ellos configuran unos grupos de nociones que se intersecan parcialmente entre sí mediante proteicos «parecidos de familia» (Wittgenstein). Estas ideas oscilan entre dos polos conceptuales de definiciones, que respectivamente pueden ser llamados: racionalidad en sentido estricto y racionalidades en sentido amplio [supra $\S$ III.1.E].

Para las ciencias sociales, en cuanto al primer polo [ $\left[\right.$ III.1. $\left.\mathrm{E}_{1}\right]$ sigue siendo válida, como núcleo básico de orientación general, la fundamental categoría Zweckrationalität delimitada como lo hizo Weber: «Actúa racionalmente con arreglo a fines quien oriente su acción por el fin, medios y consecuencias implicadas en ella, $y$ para lo cual sopese racionalmente los medios con los fines, los fines con las consecuencias implicadas y los diferentes fines posibles entre sí; en

González Amuchástegui, 1994; Gottlieb, 1968; Haba, 1977, 1996a y 2014; Horak, 1969; Horn, 1962; Instituto..., 1994; Jackson, 1987; Kriele, 1977; Perelman, 1979; Priester, 1970; Schlink, 1972; Struck, 1971 y 1977; Viehweg, 1987; Villey, 1976.

61 En Haba, 2016, son puestas de manifiesto (con mucho detalle) netas contradicciones entre ideas jurídico-valorativas básicas. 
todo caso, pues, quien no actúe ni afectivamente (emotivamente, en particular) ni con arreglo a la tradición» [Weber, 1964, p. 21 (§ 2.4)]. Y, si se quiere, con ámbito más global de aplicación cabría señalar el uso lingüístico que califica de racionales a razonamientos firmemente intersubjetivos como los científicos en general (aunque no se refieran a unas relaciones de medios a fines), inclusive los de las ciencias sociales cuando no son ideológico-doctrinales, $y$ las aplicaciones no controversiales de aquellos: en tal sentido, «pensar racionalmente consiste en que las conclusiones a que se llegue estén basadas en unos razonamientos cuya validez sea intersubjetivamente controlable» [Haba, 2012, p. 202 $]^{62}$.

En cambio, el segundo polo de acepciones [§ III.1.E ${ }_{2}$ ], mucho más anchas y asimismo señaladamente mas elásticas, lo conforman aquellas nociones de racionalidad que combinan dos caras: cierto sentido descriptivo, casi siempre bastante vago, el cual ahí viene apoyado por un neto sentido emotivo-valorativo de aprobación ${ }^{63}$. Lo que se predica como «racionalidad» consiste, para este segundo grupo, en: a) un orden, tiene cierta estructura, sus elementos básicos no están (o en todo caso se «ven» como no estando) ligados arbitrariamente o al azar; $b$ ) y ese orden tanto si es producido por la propia conciencia del sujeto que lo aprehende, como si radica en las «cosas» mismas con que este se encuentra ahí (naturaleza o sociedad), o si se manifiesta en ambos extremos (sujeto-objeto) se tiene por sobreentendido que él está bien justamente por ser así es considerado altamente recomendable, se presupone que le es intrínseca la cualidad de encarnar unos valores positivos-.

2. Ninguna de esas dos grandes categorías de racionalidad queda libre de indeterminaciones, pero la segunda las ofrece en grados amplísimos (más no se ha dejado de señalar insuficiencias aun en cuanto a la forma como

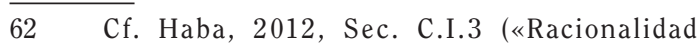
(en sentido estricto) como razonamiento intersubjetivo»); más detalladamente en Haba, 1990, $\S \S$ III-V .

Cf. Stevenson, 1971: esp. caps. I, VI y IX.
Weber presenta la primera $\left.{ }^{64}\right)$. En virtud de su componente (b), la palabra «racional» funciona como término característicamente apto para introducir «definiciones persuasivas» (Stevenson) en discursos de la teoría social ${ }^{65}$, aparece utilizada como fórmula vacía ${ }^{66}$ (o muy poco menos).

La mayoría de los autores reservan el uso de dicha palabra para denotar las clases de razones y de conductas que consideren deseables, de acuerdo con los presupuestos teorético-científicos o político-ideológicos a que respectivamente se adhieran ellos mismos. De ahí que, si ese término es tomado en su sentido amplio, resulta que hay tantos modelos de «racionalidad» cuantas son las escuelas filosóficas que entre sí discuten acerca del sentido que aquella tiene o debiera tener: racionalidad empírico-analítica [Hempel, 1979], racionalidad racionalista-críti$\mathrm{ca}^{67}$, racionalidad de tipo lógico-formal (lógica deóntica, etc.), racionalidad «sistémica» (las tenidas por tales), racionalidad fenomenológica [Schutz, 1974], racionalidad histórico-evolutiva [Toulmin, 1977], racionalidad dialógico-constructivista (Escuela de Erlangen) [Kamlah/ Lorenzen, 1973], racionalidad estructuralista ${ }^{68}$,

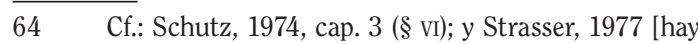
extractos en Haba, 2010a, Sec. F.IV (\#162, p. 237 y ss.: «Crítica a la concepción clásica sobre el papel del método en la ciencia»)]. Sin embargo, téngase en cuenta que hay maneras también de precisar aun más dicha racionalidad, o sea, acudir a formas de ella que son «fuertemente» intersubjetivas [supra nn. 30 y 32], si es adecuado para prevenir confusiones [cf.:Gibson, 1974; Mosterín, 1978; Priester, 1970].

Cf. Stevenson, 1971. Vid. también Haba, 2012, Sec. C.I., § 7 («Múltiples modalidades de "racionalidad", carácter persuasivo de esta palabra) y $\S$ 10 («Desacuerdos prácticos: argumentos y persuasión»).

66 Cf.: Degenkolbe, 1965; Macdonald, 1951; Weldon, 1953. Vid. también Haba, 2012, Sec. D.II.3 («Fórmulas vacías pseudonormativas»); hay materiales adicionales en Haba, 2016, Sec. G.Iv (p. 245 y ss.: «Fórmulas vacías en su función de ideología») y \# 332 (p. 357 y ss.: «Del catálogo "Saludos a la bandera"»).

67 Vid. sobre todo los estudios de Albert: esp. 1973b y 1978.

68 Cf. Arnaud, 1981: esp. pp. 15-32; y $\S ~ 3.3 .1 .2,3.3 .3$, 4.1 .2 y 4.2 . 
racionalidad dialéctico-negativa ${ }^{69}$, racionalidad dialéctico-discursiva ${ }^{70}$, racionalidad marxista-leninista ${ }^{71}$, racionalidad «hermenéutica ${ }^{72}$, racionalidad argumentativa o retórico-argumentativa ${ }^{73}$ 0 argumentativo-«procesal $»^{74}$ o lo racional como «razonable» ${ }^{75}$, y demás. A su vez, cada una de esas grandes tendencias aparece entendida de maneras variadas según unos u otros autores.

Cada concepción se presenta como opuesta a unos respectivos contramodelos de pensamiento que ella califica de «irracionales», o en todo caso entiende que estos son muy insuficientemente racionales: «falsa» racionalidad, racionalidad «recortada» 0 «menguada», $y$ demás. Así resulta que, al fin de cuentas, también el término «irracional» ofrece una gama de sentidos que es paralela, más o menos, a la de los que recibe la palabra «racional».

Y puesto que hay distintas modalidades del racionalismo como «ideología», correlativamente resultan ser más o menos «ideológicas» muy buena parte también de las concepciones

$69 \quad$ Cf.: Adorno, 1975; Habermas, 1973; Jay, 1974; Marcuse, 1969 (§ 7) y 1972.

70 Cf.: Habermas, 1985 y 1989. Crítica: Haba, 2010b, cap. V-6 (p. 217 y ss., «La variante Habermas: comunicación por el asteroide Situación-Ideal-deHabla (meneando discursos en el sombrero-galera de los "sí/no, pero no/sí")» y Apéndice (p. 244 y ss., «A modo de ilustración: "La ética del discurso universal”, ipero in vivo!»); o véase Revista de Ciencias Sociales (Universidad de Costa Rica), N. 73-74, 1996, p.147 y ss.

71 Cf.: Heiseler, 1970; Lukács, 1976: Crítica: Marcuse, $1969(\S 3)$.

72 Cf.: Apel/Gadamer/Habermas, 1971; Gadamer, 1977; Ricoeur, 2010. Críticas: Haba, 1978 [o, más breve, en 1990: Apéndice 4); imprescindibles son Albert, 1975 y 1994, y Stegmüller, 1975.

73 Cf.: Alexy, 1988 y 1989; Atienza, 2013; Gómez Giraldo, 2003; Haba, 1990 (Apéndice 2) y 2012 (Sec. C.I.8, «Argumentación y auditorios»; Sec. C.I.12, «La "nouvelle rhétorique"») y 2014; Kooperschmidt, 1980; Naess, 1975; Perelman, 1979; Perelman/ Olbrechts-Tyteca, 1989; Piacenza, 1998; Rother, 1972; Salas, 2017; Sarlo, 1994; Struck, 1971 y 1977.

Cf.: Alexy, 1988; Carrión Wam, 1996.

75 Cf.: Aarnio, 1991; Haba, 2012 (Sec. C.I: $§ \S 6[\ll L o$ razonable») y 11 [«Conclusión: ¿lo racional o lo razonable?») y 2018; Recaséns Siches, 1971. sobre qué son racionalidad e irracionalidad para cuestiones de las ciencias sociales. (Kolakowski, el filósofo más lúcido en la segunda mitad del siglo xx, supo diferenciar entre distintas modalidades del «racionalismo», respectivamente como: «doctrina», «conocimiento», «reforma de la filosofía», «normativo» — para la conducta, para el pensamiento, regla de verificaciónel «mundo de los valores», etc. [Kolakowski, 1970]). Esas ideologizaciones se hacen presentes señaladamente como postulaciones en cuanto a la llamada «Razón práctica».

Si bien se mira, también a los etiquetados «racional» o «razonable» se suele acudir como unas maneras discursivas de legitimar algo así como lo que Pareto llamó derivaciones ${ }^{76}$ : tales o cuales expedientes argumentativos disimuladores, los cuales tienen mucho curso señaladamente en la teoría política y en los razonamientos jurídicos. En efecto, no raramente, el uso de esos términos se constituye al fin de cuentas en todo un «obstáculo epistemológico» [Bachelard, 2000] contra la comprensión realista de los fenómenos en cuestión; así en fundamentaciones de sentencias judiciales y en las concepciones idealistas al respecto que ostentan la voz cantante en la actual Teoría del Derechoo ${ }^{77}$, pero también en prestigiosas orientaciones de la teoría social (p. ej.: Rawls, Habermas ${ }^{78}$ ).

En cuanto al derecho, el sentido laudatorio de este término salta a la vista en los enfoques apologéticos sobre el razonamiento judicial, este al que esos autores llaman «racional» o «razonable»: cf., por todos, al pensador original de tal tendencia, por cierto el más lúcido y diáfano en el seno de ella [Perelman, $1979^{79}$; para la crítica

76 «Las derivaciones comprenden razonamientos lógicos, sofismas, manifestaciones de sentimientos, utilizados para derivar; son manifestaciones de la necesidad de razonar que siente el hombre. Si esta necesidad se satisficiera sólo con los razonamientos, no habría derivaciones, y en vez de ellas se tendrían teorías lógico-experimentales» (Pareto, 1980, p. 56).

77 Véase: [84], [87], [91].

78 Véase Haba, 2009 y 2010b (para este último sitio, los lugares señalados supra en la n.70).

79 Ese texto corresponde a la segunda etapa en el pensamiento de dicho autor (a diferencia de su 
realista ante esa ideología profesional, vid. Haba, 2010c, 2011 y 2014]. Acerca de los discursos jurídicos, mas también para la ética, la política, etc., nos encontramos así con variedad de teorizaciones idealistas (es «algo así como poner el carro delante del caballo...», señala Toulmin ${ }^{80}$ ) en las reflexiones académicas sobre esa materia, distintas «cirugías plásticas» ${ }^{81}$ al respecto. Estos autores $\left(\right.$ Rawls $^{82}$, Habermas ${ }^{83}$, Dworkin ${ }^{84}$, Alexy ${ }^{85}$, Alchourrón y Bulygin ${ }^{86}$, Nino ${ }^{87}$, Ferrajoli ${ }^{88}$,

etapa anterior, rotundamente crítica: Perelman/ Olbrechts-Tyteca, 1989). [Sobre dicho cambio, véase Haba, 2010c: § I.2, «Rasgos fundamentales de la concepción ilusionista sobre las argumentaciones que efectúan los juristas: su "teoría estándar"», in limine].

Cf. Atienza/Jiménez Redondo, 1993: p. 330 y s. Pero esa cita corresponde a una etapa en el pensamiento de Toulmin que es posterior a la de su idealista enfoque originario: The Uses of Argument, 1958 [véase $m$ fra n. 87].

Así lo dice, con tanto graficismo, Courtis, 2006: p. 14.

De ese autor y los demás mencionados en el interior de este paréntesis, cf. respectivamente sus obras indicadas en la Bibliografía que está al final del presente estudio. - Análisis crítico sobre el planteamiento de Rawls: Haba, 2009.

Crítica: sitios señalados supra, n. 70.

Crítica: Haba, E. P., «El bluff Dworkin. Su rehabilitación del no-saber en la actual Teoría del Derecho [Versión completa]», Criterio Jurídico, vol. 9, n I, 2009, pp. 155-258 (http://revistas.javerianacali.edu.co/index.php/criteriojuridico/article/ view/326/1170); una versión mucho más breve se publicó antes en Doxa, n 24, 2001, pp. 165-201.

Crítica: Haba, 1998.

86 Crítica: a la obra de estos dos autores (1975), muy renombrada (sobre todo por su versión original en inglés), le son plenamente aplicables las observaciones generales que contiene Haba, 1996a.

Le son aplicables las básicas críticas generales puntualizadas por: las observaciones de Toulmin en Atienza/Jiménez Redondo, 1993 (esp. p. 338 y ss. [y ver supra n. 80]); Haba, 1998 y 2007 y 2013.
Aarnio y Atienza ${ }^{89}$, etc. ${ }^{90}$ ) consagran principalmente sus estudios a pergeñar tales o cuales modelos impolutos de pensamiento «racional» 0 «razonable (jciencia jurídica «exquisita»! ${ }^{91}$ ), dando sin más por pre-supuesto que el derecho funciona o podría llegar a funcionar como obra de locutores jurídicos ideales y condiciones institucionales ideales.

En definitiva, las controversias teoréticas sobre qué sea de veras «racional» o «razonable», y qué no lo sea en absoluto o no suficientemente, suelen consistir en desacuerdos sobre simpatías doctrinarias hacia tales o cuales definiciones estipulativas. Y estas son llevadas adelante como si ahí viniera a tratarse, al fin de cuentas, ni más ni menos que de unas definiciones reales $^{92}$ (jesencialismo! ${ }^{93}$ ) para la materia en cuestión.

Mas no es fácil sustituir el término «racional» por otras palabras que sean de uso normal y suficientemente preciso, para no dejar de diferenciar - frente a ese maremágnum de significados vago-emotivizantes encubiertos por quel mismo también- determinados círculos de referentes precisos y muy importantes del pensamiento científico sibre ciertas materias. Esto es, distinguir las condiciones para alcanzar tales o cuales maneras específicas de la «racionalidad» en sentido estricto [supra $\S \mathrm{I}$ :

89 Crítica: Haba, 2014 (esp.: p. 117 y ss., «Callar o no callar... that is que question!» [antes en Doxa, $\mathrm{n}^{\circ}$ 33, 2010, pp. 369-398.]; p. 201 y ss., «Avatares...» [antes 2011]) y 2018; Salas, 2017. - Por cierto, Atienza no omite reconocer su gran afinidad con autores como los antes mencionados, especialmente algunos de ellos: Dworkin, Alexy, Nino, en cierta medida aun Ferrajoli [cf. Atienza, 2013: p. ej. págs. 561 in fine y 806].

90 De manera general sobre el «constructivismo» jurídico (corriente a la que pertenecen, de unas u otras maneras, los enfoques de todos ellos), vid. Haba, 2007.

$91 \quad$ Véase Haba, 2015.

92 Supra: n. 3.

93 Supra: n. 4. 
tipo 3], con vistas a encarar justamente así las cuestiones de que se trate.

Sea o no sea que se adopte esta última orientación, para la claridad del pensamiento (vale decir, icuando no se procura antes bien «inmunizarlo»!94) resulta lo más aconsejable dejar expresa constancia sobre lo siguiente, en cada caso o especie de casos donde se entienda que ahí intervienen o deberían intervenir decisivamente unos componentes que se califica como instancia racional: a) el hecho de que cualquiera de las definiciones de ese término es OPCIONAL - por tanto, elegirla es básicamente asunto de «conveniencia», ya sea cognitivo-intelectual o como retórica, no una cuestión de verdaderoo-falso (salvo en cuanto no se pretenda sino dar cuenta descriptiva de un uso determinado al respecto en cierto grupo de locutores)—; $b$ ) y sobre todo aclarar CUÁL, entre las múltiples alternativas semánticas disponibles para ello, es la acepción específica recogida por el locutor. [Probablemente tal alternativa calce con alguna de las señaladas en el presente examen, o eventualmente hasta podría ser oportuno llegar a hacer ver si ahí a cualquiera de ellas corresponda incorporarle (itanto mejor!) ciertas notas de precisión adicionales; o bien, si fuera del caso, hacer ver aun cierta opción semántica al respecto que aquí haya pasado desapercibida].

De todos modos, muy difícilmente alguien reconocerá que su propia manera de usar la categoría «racional» comporta una aplicación voluntarista —opción entre bandos de doctrina- de ese término. Los «ir-racionales» son siempre, icómo no!, otras personas. ¿Hay quien no esté convencido de que son «racionales» o «razonables» —ifaltaría más! — las ideas que él estima acertadas? Tal destino para los usos de estas palabras es, por cuanto se ve, no menos inevitable también para los juristas ${ }^{95}$; abunda asimismo en teóricos de otras esferas

$94 \quad$ En los estudios de Albert, véase las frecuentes referencias a las «estrategias de inmunización» (Immunisierungsstrategien) discursivas usadas para esquivar el tener que abordar las críticas a fondo.

Véase [76]. para la llamada Razón práctica y de la filosofía social en general ${ }^{96}$.

\section{B) UNA BIBLIOGRAFÍA PARA «ACIONALIDAD» ${ }^{97}$}

Nota.- Si bien la lista consignada es no poco extensa, obviamente no abarca, ni podría hacerlo (ella misma o cualquier otra), sino alguna escasa porción del maremágnum de estudios publicados en cuyo título se indica la palabra «racionalidad» o «racional», y ni qué hablar de tantos otros trabajos que en el seno de su propia temática abarcan también cuestiones denominadas de esa manera. Me he fijado como límite, para confeccionarla, el número de 200 títulos principales. Aun siendo esta una cifra no poco elevada, por supuesto «no están todos los que son», la innumerable legión de estudios convocados por tal homonimia, y seguramente faltan inclusive muchos cuyo interés puede ser similar o hasta superior al de otros entre los que sí están. Pero me parece que, así y todo, la amplísima variedad de los puntos de vista relativos a dicho término comprendidos en esta enumeración, expuestos principalmente en textos del siglo pasado e incluso llegando hasta fechas muy recientes, hace que ella pueda resultar bastante representativa del multifacético caleidoscopio existente al respecto; pienso que difícilmente (¡mas no es imposible!) alguna perspectiva fundamental ubicada dentro la

$96 \quad$ Ni aun autores que postulan eso que llaman «postmodernismo» reconocen de buena gana que sus propias afirmaciones vendrían entonces a ser «irracionales» ellas también (p. ej., Bouveresse [38] revela una experiencia suya al respecto, ante un colega de dicha corriente, a quien por cierto no le pareció - en la discusión entre los miembros de un tribunal de tesis- que sus propios puntos de vista sostenidos fuesen «irracionales»). - Sobre dicha charlatanería en general (Derrida y demás), vid. el concluyentemente higienizador examen de Sokal y Bricmont [175], complementado por [36].

97 La presente lista es muchísimo más amplia, como también puesta al día, que la incluida en la versión anterior [supra n. 8]. Para las obras que fueron publicadas originalmente en idiomas extranjeros se indicaron estas mismas en dicho sitio; aquí las referencias se efectúan a las versiones respectivas en español, cuando hay publicadas tales. 
vasta homonimia de dicho término haya sido dejada de lado aquí. [En particular, creo haber conseguido no dejar de incluir, entre los trabajos enumerados aquí, unos tipos de exámenes claves sobre cuyas decisivas puntualizaciones, inusualmente realistas, se hace abstracción en los trabajos «técnicos» más mencionados que responden al afán de precisar formalmente dicho término. Tal vez pueda ofrecer algún valor indicativo llamar la atención hacia la existencia de estudios como estos justamente, por lo cual me tomo la libertad de destacarlos mediante el recurso tipográfico de hacer resaltar con VERSALITAS (en negrita) el nombre de su respectivo autor].

\section{REFERENCIAS}

Aarnio, A. (1991). Lo racional como razonable. Un tratado sobre la justificación jurídica (trad. E. Garzón Valdés). Madrid: Centro de Estudios Constitucionales.

Adorno, T. y Popper, K. et ál. (1973). La disputa del positivismo en la sociología alemana (trad. J. Muñoz). Barcelona-México: Grijalbo.

Adorno, T. W. (1975). Dialéctica negativa (trad.. J. M. Ripalda) [esp. Parte III, cap. I]. Madrid: Taurus.

Agassi, J. y Jarvie, E. C. (Eds.) (1985). Rationality: the Critical View. The Hague: Matinus Nijhoff.

ALBERT, H. (1973a). «El mito de razón total. Pretensiones dialécticas a la luz de una crítica no dialéctica» $y$ «¿ंA espaldas del positivismo?». En Adorno/Popper et ál., 1973: 181-219 y 251-286.

ALBERT, H. (1973b). Tratado sobre la razón crítica, (trad. R. Gutiérrez Girardot). Buenos Aires: Sur.

Albert, H. (1975). Transcendentale Träumerein. Karl Otto Apels Sprachspiele un sein hermeneutischer Gott (Ensoñaciones trascendentales. Los juegos de lenguaje de Karl Otto Apel y su dios hermenéutico). Hamburg: Hoffmann und Campe.

ALBERT, H. (1978). Traktat über rationale Praxis (Tratado sobre la práctica racional). Tübingen: J. C. B. Mohr (Paul Siebeck).

Albert, H. (1987). Kritik der reinen Erkenntnislehre. Das
Erkenntnisproblem in realistischer Perspektive (Crítica de la teoría pura del conocimiento. El problema del conocimiento en perspectiva realista). Tübingen: J. C. B. Mohr (Paul Siebeck).

Albert, H. (1994). Kritik der reinen Hermeneutik. Der Antirealismus und das Problem des Verstehens (Crítica de la hermenéutica pura. El antirrealismo y el problema de la comprensión). Tübingen: J. C. B. Mohr (Paul Siebeck).

Albert, H. (2007). La Ciencia del Derecho como Ciencia Real (Pres., trad. y nn.: M. E. Salas). México: Fontamara.

Alchourrón, C. E. y Bulygin, E. (1975). Introducción a la metodología de las ciencias jurídicas y sociales. Buenos Aires: Astrea. [Es la traducción al español de Normative Systems (Viena, Springer, 1971), efectuada por sus propios autores].

Alexy, R. (1988). «La idea de una teoría procesal de la argumentación jurídica» (trad. C. De Santiago). En Garzón Valdés, E. (Comp.), Derecho y Filosofía, 43-57. México: Fontamara 50. [Comentario: Carrión Wam, 1996].

Alexy, R. (1989). Teoría de la argumentación jurídica. La teoría del discurso racional como teoría de la fundamentación jurídica (trad. M. Atienza e I. Espejo). Madrid: Centro de Estudios Constitucionales. [Análisis crítico: Haba, 1998].

Anacker, U. (1974). «Vernunft». En Krings, H. y Baumgartner, H. M. y Wild, C. (Eds.). En Handbuch Philosophischer Grundbebriffe (Manual de conceptos filosóficos fundamentales), vol. vI, 15971612. München: Kösel.

Apel, K. O., Gadamer, H.-G. y Habermas, J. (1971). Hermeneutik und Ideologiekritik (Hermenéutica y crítica de la ideología), Frankfurt: Suhrkamp. [Crítica: Albert, 1975 y 1994; Haba, 1978 y 1990 (Apéndice 4)].

Archives de Philosophie du Droit, vol. 23 (1978). Formes de rationalité en droit. Paris: Sirey.

Arnaud, A.-J. (1981). Critique de la raison juridique 1. Où va la Sociologie du Droit?, 
Paris: Librairie Générale de Droit et de Jurisprudence. [Comentario: Haba, 1990 (Apéndice 5)].

Arnaud. A.-J. (1988) (Dir.). Dictionnaire Encyclopédique de Théorie et de Sociologie du Droit, Paris-Bruxelles: Librairie Génerale de Droit et de Jurisprudence y E. Story-Scientia.

ARNOLD, T. W. (1962). The Symbols of Government. New York: Harbinger Book.

Arnswald, U. y Schütt, H.-P. (2011) (Eds.). Rationalität und irrationalität in den Wissenschaften (Racionalidad e irracionalidad en las ciencias). Wiesbadaden: vs Verlag für Sozialwissenschaften.

Arrow, K. J. (1963). Social Choice and Individual Values. New Haven-London: Yale University Press.

Atienza, M. y Jiménez Redondo, M. (1993). «Entrevista con Stephen E. Toulmin» (trad. M. Jiménez Redondo). Doxa, 13: 329-356.

Atienza, M. (2013). Curso de argumentación jurídica. Madrid: Trotta. [Critica básica: Haba, 2014 y 2018; Salas, 2017].

Aubenque, P. (1963). La prudence chez Aristote. Paris: Presses Universitaires de France.

Bachelard, G. (1973). El compromiso racionalista (trad. H. Beccacece). Buenos Aires: Siglo Veintiuno.

Bachelard, G. (1978). El racionalismo aplicado (trad. I. A. de Ramos). Buenos Aires: Paidós.

BACHELARD, G. (2000). La formación del espíritu científico. Contribución a un psicoanálisis del conocimiento objetivo (trad. J. Babini). México: Siglo xxı.

Bartley, W. W. (1964). «Rationality vs. the Theory of Rationality». En Bunge, M. (Ed.), The Critical Approach to Science and Philosophy, 3-31. New York: Free Press of Glencoe.

Bennet, J. (1964). Rationality: An Essay Towards an Analysis. London: Routledge \& Kegan Paul.

BERGER, P. y LUCKMANN, T. (1968). La construcción social de la realidad (trad. S. Zuleta, rev. técn. M. Giménez Zapiola). Buenos Aires: Amorrortu.
Bermúdez, J. L. (2009). Decision Theory and Rationality. Oxford: Oxford University Press.

Blanché, R. (1967). La science actuelle et le rationalisme. Paris: Presses Universitaires de France.

BLANCHÉ, R. (1973). Le raisonnement. Paris: Presses Universitaires de France.

Bloch, E. (1983). Sujeto-Objeto. El pensamiento de Hegel (trad. W. Roces). México: Fondo de Cultura Económica.

Bobbio, N. (1985). «La razón en el derecho (Observaciones preliminares)» (trad. A. Ruiz Miguel). Doxa, 2: 17-26.

Bouveresse, J. (2001). Prodigios y Vértigos de la Analogía. Sobre el abuso de la literatura en el pensamiento (Prol. A. Sokal y J. Bricmont; trad. L. Wittner; rev. técn. G. Livov, O. Kulesz y M. Arias). Buenos Aires: Libros del Zorzal.

Bouveresse, J. (2011). Raison et religion: en quoi consiste le desaccord et peut-il être traité de façon rationnelle ?. Paris: Collège de France (http://books.openedition.org/cdf/2060).

Bouveresse, J. y Tiercelin, C. y Djigo, S (2012). La raison et le réel. Lille: citéphilo (www. citephilo.org/manif/la-raison-et-le-réel). [Ver también: Tiercelin, 2014].

BRECHT, A. (1963). Teoría política. Los fundamentos del pensamiento político del siglo $x x$ (trad. J. M. Mauri). Buenos AiresBarcelona: Depalma-Ariel.

Bunge, M. (1985). Racionalidad y realismo [esp. cap. 1], Madrid: Alianza Universidad.

Carrión Wam, R. (1990). «Filosofía del derecho positivo: notas para una investigación crítica sobre los fundamentos de la "racionalidad práctica jurídica"». En IV Jornadas de Investigación Filosófica, pp. 1-5. Caracas: Universidad Central de Venezuela.

Carrión Wam, R. (1994a). «Los derechos humanos y la razón práctica jurídica positiva». En El trabajo filosófico de hoy en el continente. Memorias del xIII Congreso Interamericano de Filosofía, 977-982. Bogotá: Sociedad Interamericana de Filosofía/Sociedad Colombiana de Filosofía-Universidad de los Andes. 
Carrión Wam, R. (1994b). «Razón Jurídica: Legalidad y Legitimidad». Frónesis (Universidad del Zulia) vol. I-n ${ }^{\circ} 2: 195-$ 201.

Carrión Wam, R. (1996). «El modelo de la ética procedimental: formalismo $y$ argumentación en el Derecho». Revista de Filosofía (Universidad del Zulia), Número Especial II/III: 121-123.

Castro Rivera, A. y Meliante Garcé, 1. (1993). «Una visión dialéctica del Derecho: Michel Villey». En Instituto de Filosofía del Derecho, 1994: 61-88.

Coleman, J. S. (1990). Foundations of social theory. Cambridge (Massachusetts): Belknap Press.

Correas, O.(2009). Razón, retórica y derecho. Una visita a Hume. México: Coyoacán.

Courtis, C. (2006) (Ed.). Observar la ley. Ensayos sobre metodología de la investigación jurídica, Madrid: Trotta. [Comentario: Haba, 2012 (p. 839 y ss.: «Cuestiones metodológicas de la investigación jurídica en serio (pero básicamente ilusa)»; versión previa en Isonomía, 27-2007, pp. 307-213].

DEBRAY, R. (1963). Crítica de la razón política (trad. - con muchos defectos- P. Calvo). Madrid: Cátedra.

DEGENKOLBE, G. (1965). «Über logische Struktur und Gesellschaftliche Funktionen von Lehrformeln» (Sobre estructura lógica y funciones sociales de las fórmulas vacías). Kölner Zeitschrift für Soziologie und Sozialpsicologie, 17: 327-338.

DEWEY, J. (1924). « Logical Method and Law». Cornell Law Quarterly, 10: 17-27.

DUBOS, R. (1967). Los sueños de la razón ciencia y utopía- (trad. J. Almeda). México: Fondo de Cultura Económica.

Elster, J. y Hylland, A. (Eds.) (1986). Foundations of social choice theory. Studies in rationality and social change. Cambridge: Cambridge University Press.

Elster, J. (1990). «Racionalidad, moralidad y acción colectiva». Zona Abierta, 54-55: 43-67.

Esser, J. (1972). Vorverständnis und Methodenwahl in der Rechtsfindung.
Rationalitätsgrundlagen richterlicher Entscheidungspraxis (Precomprensión $y$ elección del método en las maneras de hallar el derecho. Fundamentos de racionalidad en la práctica de la decisión judicial). Frankfurt: Athenäum Fischer Tashenbuch ( $2^{\text {a }}$ ed.). [Resumen y comentario: E.P. Haba, «Precomprensión, racionalidad y métodos, en las resoluciones judiciales», Doxa, 22 (1999), pp. 49-78].

Etzioni, A. (1980). La sociedad activa. Una teoría de los procesos societales y políticos (trad. E. Fuente Herrero, rev. J. Culebras Abril) [esp. caps. xг y xII]. Madrid: Aguilar.

Ferrajoli, L. (1998). Derecho y razón. Teoría del garantismo penal (trad. P. A. Ibáñez et al.), Madrid: Trotta. [Análisis crítico: Salas, 2012].

Ferrater Mora, J. (1979). De la materia a la razón. Madrid: Alianza Editorial.

Feyerabend, P. K. (1981). Tratado contra el método. Esquema de una teoría anarquista del conocimiento (trad. D. Ribes). Madrid: Tecnos.

Feyerabend, P. K. (1984). Adiós a la razón (trad. J. R. de Rivera). Madrid: Tecnos.

Foucault, M. (1971). L'ordre du discours. Paris: Gallimard, 1971.

Foulquié, P. (1959). La dialectique. Paris: Presses Universitaires de France.

FRANK, J. (1931). «Mr. Justice Holmes and Non-Euclidean Legal Thinking». The Cornell Law Quarterly, 17: 568-603.

Gadamer, H.-G. (1977). Verdad y Método. Fundamentos de una hermenéutica filosófica (trad. A. Agud Aparicio y R. de Agapito), Salamanca: Sígueme. [Análisis crítico: Albert, 1994; Haba, 1978 y 1990 (Apéndice 4); Stegmüller, 1975].

GIBSON, Q. (1974). La lógica de la investigación social (trad. J. Melgar Botassis) [esp. pp. 60 y ss. («Razones») y cap. xIv («El supuesto de la racionalidad»)]. Madrid: Tecnos.

Gimbernat, J. A. (1983). Ernst Bloch: utopía y esperanza. Madrid: Cátedra.

GÓMEZ GIRALDO, A. L. (2003). Seis lecciones sobre teoría de la argumentación. Cali: Alego. 
González Amuchástegui, J. (1994). «El análisis económico del derecho: algunas cuestiones sobre su justificación». Doxa, 15-16, vol. 2: 929-944.

GOTTLIEB, G. (1968). The Logic of Choice. London: George Allen \& Unwin.

GRANGER, G.-G. (1972). La Razón (trad. N. Rivaroba). Buenos Aires: Editorial Universitaria de Buenos Aires.

Granger, G.-G. (2004). Rationalité et raisonnement. Université de tous les savoirs (www.canal-u.tv/video/universite_de_ tous_les_savoirs/rationalite_et_raisonnement.896).

Guedez, A. (1976). Lo racional y lo irracional. Introducción al pensamiento de Michel Foucault (trad. A. V. Soto, superv. L. de France). Buenos Aires: Paidós.

Haba, E. P. (1977). «Rationalität der Autoritäten oder Autorität der Rationalität?» (¿Racionalidad de las autoridades o autoridad de la racionalidad?). Rechtstheorie, 8(2): 145-163.

Haba, E. P. (1978). «Hermeneutik contra Rechtswissenschaft» (Hermenéutica contra ciencia jurídica). Archiv für Rechts- und Sozialphilosophie, Ixiv(2): 163-181. [Presentación muy resumida en Haba, 1990 (Apéndice 4).]

Haba, E. P. (1990). «Racionalidad y método para el derecho: ¿es eso posible?». Doxa, 7 y 8: 169-247 y 241-270. Versión revisada y ampliada: Revista de Ciencias Jurídicas (Universidad de Costa Rica), 66 y 67 (mayo-agosto y set-dic.), 67-134 y 169-244; esta versión fue recogida también en una edición independiente del mismo año. [Versiones previas para la Parte I: «Rationalité et méthode dans le droit», Archives de Philosophie du droit, 23 (1978, Formes de rationalité en droit), 265-293; «Lo racional y lo razonable», Revista de Filosofía de la Universidad de Costa Rica, 43 (1978), 1-32].

Haba, E. P. (1996a). «Lógica formal y Derecho», Enciclopedia Jurídica Omeba, Apéndice VII, 625-632, Buenos Aires: Driskill. [Presentación revisada y levemente ampliada: Haba. 2015, cap. iv (pp. 207 y ss.: «Racionalidad mecánica: lógica deóntica (su esterilidad como conocimiento y su inocuidad para servir como guía en las prácticas jurídicas efectivas)». Un poco más breve: Haba, 2012 (Sec. D). Primera versión, mucho más reducida: Haba, 1990 (Apéndice 1)].

Haba, E. P. (1996b). «Una discusión: ¿Quiénes son los "irracionalistas" en la Teoría del Derecho?». Doxa, 19: 385-402. [Versión revisada y ampliada, en: J. F. Palomino Manchego (Dir.), Discusión sobre el carácter anti-científico del Derecho. Lima, Grijley, pp. 271-315. Presentación nuevamente revisada en Haba, 2015 (cap. iii)].

Haba, E. P. (1998). «Teorización constructivista como "forma de vida" (Sobre "formas $y$ reglas" del discurso jurídico en los tribunales inexistentes)». Doxa, 21-I: 147170. [Versión revisada y algo ampliada en Haba, 2015 (cap. vi: «Ciencia jurídica imaginaria»)].

Haba, E. P. (2000). «Semiótica ilusionista y semiótica desencantadora. Mitomanías de la Razón "constructivista”: ¿racionalidad de los juristas o racionalidad de los iusemióticos?». Doxa, 23: 561-596.

Haba, E. P. (2007). «Contra la "Santa (charla-) Familia". Anclajes básicos de la vocación astronáutica promovida por Rawls, Habermas y otros apóstoles del wishful thinking académico». Doxa, 30: 491-524. [Es una traducción parcial de «Standortbestimmung zeitgenössischer Rechtstheorie - Rawls, Dworkin, Habermas und andere Mitglieder der "Heiligen (Rede-)Familie"» (Ubicación de la Teoría del Derecho contemporánea - Rawls, Dworkin, Habermas $y$ otros miembros de la "Santa (charla-)Familia"), en System der Rechte, demokratischer Rechtsstaat und Diskurstheorie nach Jürgen Habermas, Habermas-Sonderheft: Rechtstheorie, 27-3 (1996), pp. 277-327, publ. 1998 (2a ed. 2004). Todos esos materiales están comprendidos en Haba, 2010b].

Haba, E. P. (2009). «Rawls: El extraterrestre raciocinante. Teoría social en tanto que 
mero divertimento discursivo (Sobre la neoescolástica social de J. Rawls como paradigma de teorización alienada)». Revista Telemática de Filosofía del Derecho, 12: 223-267. [Este texto conforma la mayor parte del cap. $V$ en Haba, 2013].

Haba, E. P. (2010a). Los juicios de valor. Elementos básicos de Axiología General. Epistemología del discurso valorativo práctico (Materiales para discernir condiciones de racionalidad en esos discursos). San José (cR): Editorial ucr ( $2^{\text {a }}$ ed., corr. y ampl.).

Haba, E. P. (2010b). Entre tecnócratas y wishful thinkers. La visión «misionera» de las ciencias sociales. Granada: Comares. [Hay unos adelantos parciales en Revista de Ciencias Sociales (Universidad de Costa Rica), Nos. 64-1994 (pp. 109-119), 70-1995 (pp. 69-81), 71-1996 (pp. 73-86), 72-1996 (pp. 171-186), 73/74-1996 (pp. 145-157). También: «Variantes del pensamiento escapista en una moderna "Santa Familia": sobre Rawls, Habermas, etcétera (Acerca de la concepción "misionera" para las ciencias sociales)» (principalmente es examinado lo de Habermas: pp. 116 y ss.), Sistema, 137, marzo 1997, pp. 109-125].

Haba, E. P. (2010c). «Razones para no creer en la actual Teoría (ilusionista) de la Argumentación. Papel que tales teorizaciones cumplen como más nueva ideología de legitimación con respecto, especialmente, al discurso jurídico profesional (Observaciones sobre la falaciocidad de ellas como descripción del pensamiento judicial y también acerca de su inocuidad como propuesta práctica para este mismo)». Doxa, 33: 321-360. [También en Haba, 2014: 27-102].

HABA, E. P. (2011). «Debate sobre Teoría de la Argumentación: Avatares de lo "racional" y lo "razonable", cuando son eximidos de tener carnet de identidad (como también sobre unos ecos, en Teoría del Derecho, de la perenne dicotomía entre "El científico y el político")». Revista Telemática de Filosofía del Derecho, 14: 239-316. [Recogido en Haba, 2014: 201-326 y 387398. Versión muy reducida (fragmentaria) en Doxa, 33, 2010: 409-418].

HABA, E. P. (2012). Metodología (realista) del Derecho. Claves para el razonamiento jurídico de visión social práctica, tomos i y ii (impresos) + iii (cd), San José (cr): Editorial ucr [esp. Sec. C.I: «Fundamentaciones e intersubjetividad. Lo racional y lo razonable»]. 3/4 Nueva versión de esta obra: Ediciones Olejnik, 2018 (en prensa). [Versión anterior, muchísimo más breve: Haba, E. P., 2006. Metodología jurídica irreverente. Elementos de profilaxis para encarar los discursos jurídicos terrenales Madrid: Dykinson].

HABA, E. P. (2013). «La opción capital para los razonamientos jurídicos: ¿novelas de conceptos o una tecnología social?)». Doxa, 36: 509-557. Versión revisada (algo abreviada) en empóriododireito (http://emporiododireito.com.br/?s=Enrique+Haba), 2016. [Presentación reelaborada (completa) en Haba, 2015: caps. VII-VIII].

Haba, E. P. (Coord.) (2014). Un debate sobre las teorías de la argumentación juridica. Lima-Bogotá: Palestra-Temis. [Publicaciones originales: Doxa, 33, 2010, pp. 319-450; más Haba, 2011].

Haba, E. P. (2015). La ciencia de los jurístas: ¿qué «ciencia»? De la ciencia jurídica normal a la ciencia jurídica exquisita [esp. caps. III (pp. 153 y ss.: «Racionalidad e irracionalidad en la ciencia jurídica (¿Quiénes son los "irrracionales?)») y V (pp. 235 y ss.: «Diálogo "razonable": Teoría de la Argumentación (enarbolada como nueva ideología profesional de los juristas)»], San José (c.r.): Editorial Jurídica Continental.

Haba, E. P. (2016). Axiología Jurídica Fundamental. Bases de valoración en el discurso jurídico. San José (cR): Editorial UCR ( $3^{\text {a }}$ ed., nuevamente revisada y ampliada).

HABA, E. P. (2018). «Atajos para una racionalidad juridica ilusoria: "universalidad", 
"consistencia"/"coherencia", pretensión de "corrección", lo "razonable" etc. (¿Quiénes son los juristas "iluminados"?)». Revista Telemática de Filosofía del Derecho, 21: 3-43.

Habermas, J. (1971). «Dogmatismus, Vernunft und Entscheidung. Zur Theorie und Praxis in der verwissenschaftlichen Zivilisation» (Dogmatismo, razón y decisión. Sobre teoría y práctica en la civilización cienficista). En Id., Theorie und Praxis, Frankfurt: Luchterhand, 231257. - En español: Id., 1996, Teoría y praxis (trad. D. J. Vogelmann). Buenos Aires, Sur.

Habermas, J. (1973). «Teoría analítica de la ciencia $y$ dialéctica» $y$ «Contra un racionalismo menguado de modo positivista». En Adorno/Popper et ál., 1973, 147-180 y 221-250. [Crítica: Albert, 1973a].

Habermas, J. (1985). Conciencia moral y acción comunicativa (trad. R. García Cotarelo) [esp. § III]. Barcelona: Península. [Crítica: Haba, 2018 (§ 2. in fine: «Excurso: A propósito de Habermas y otros»)].

Habermas, J. (1989). Teoría de la acción comunicativa: complementos y estudios previos (trad. M. Jiménez Redondo) [esp. parte iv]. Madrid: Cátedra. [Critica: Atienza y Jiménez Redondo, 1883; Haba, «Variantes del pensamiento escapista...» (ref. supra en Haba, 2010b; y recogido también en este último lugar, cap. V 6)].

Habermas, J. y Luhmann, N. (1971). Theorie der Gesellschaft oder Sozialtechnologie? - Was leistet die Systenforschung? (¿Teoría de la sociedad o tecnología social? - ¿Qué aporta la investigación de sistemas?). Frankfurt: Suhrkamp. [Sobre Luhmann: «La vertebral falta de referentes empíricos netos - bien diferenciables como tales - en los discursos del tipo "sistémico"-luhmanniano", en Haba, 2015 (p. 519 in fine y ss.); también en Haba, 2014 (p. 180 y ss.)].

Heiseler, J. H. et ál. (1970). Die «Frankfurter Schule» im lichte des Marxismus. Zur Kritik der Philosophie und Soziologie von Horkheimer, Adorno, Marcuse, Habermas (La Escuela de Francfort a la luz del marxismo. Para la crítica de la filosofía y sociología de Horkheimer, Adorno, Marcuse, Habermas). Frankfurt: Marxistische Blätter.

HEMPEL, C. G. (1979). La explicación científica. Estudios sobre filosofía de la ciencia (trad. N. Míguez) [esp. §§ III («La ciencia y los valores humanos») y xiI.10 («El concepto de racionalidad y la lógica de la explicación por razones»)]. Buenos Aires: Paidós.

Höffe, O. (1975). Strategien der Humanität. Zur Ethik öffentlicher Entscheidungsprozesse (Estrategias de la humanidad. Sobre la ética de los procesos de decisión públicos). FreiburgMünschen: Karl Alber.

Holis, M. (1991). Rationalität und soziales Verstehen. Wittgenstein-Vorlesungen der Universität Bayreuth (Racionalidad $y$ comprensión social. LeccionesWittgenstein de la Universidad de Bayreuth). Frankfut: Suhrkamp Taschenbuch Wissenschaft.

Horak, F. (1969). Rationes decidendi I. Entscheidungsbegründungen bei den älteren römischen Juristen bis Labeo [Rationes decidendi I. Fundamentaciones de las decisiones en los juristas romanos antiguos hasta Labeo], Aalen: Scientia.

Horkheimer, M. (1973). Crítica de la razón instrumental (trad. H. A. Murena y D. Vogelmannn). Buenos Aires: Sur.

HORN, D. (1962). Studien zur Rolle der Logik bei der Anwendung des Gesetzes (Estudios sobre el papel de la lógica en la aplicación de la ley). Berlin: Tesis presentada en la Freie Universität Berlin. [Sinopsis en Haba, 2012, t. III (Tema 10, Apéndice A, p. 663 y ss.: «Anotaciones complementarias sobre el papel de la logica en la aplicación de las leyes»)].

Instituto de Filosofía del Derecho (Facultad de Derecho-Universidad de la República) (1994). Hermenéutica y racionalidad. Montevideo: Fundación de Cultura Universitaria. 
Jackson, B. (1987). «Rationalité consciente et inconsciente dans la théorie du droit et la science juridique» (trad. D. Flore). Revue interdisciplinaire d'études juridiques, 19: 1-18.

Jay, M. (1974). La imaginación dialéctica. Una historia de la Escuela de Franfurt (trad. J. C. Curutchet). Madrid: Taurus.

Jhering, R. v. (1974). «En el cielo de los conceptos jurídicos. Una fantasía». En Bromas $y$ veras en la jurisprudencia (trad. B. H. Banzhaf), Parte iII. Buenos Aires: Ediciones Jurídicas Europa-América.

Kaltenbrunner, G. K. (Ed.) (1974). Plädoyer für die Vernunft. Signale einer Tendenzwende (Alegato en pro de la razón. Señales de un cambio de tendencia). Basel-Vien: Herdebucherai Initiative 1.

Kamlah, W. y Lorenzen, P. (1973). Logische Propädeutik. Vorschule des vernünftigen Redens (Propedéutica lógica. Enseñanzas preliminares para el discurso racional). Mannheim-Wien-Zürich: Bibliographisches Institut.

Kilian, W. (1974). Juristische Entscheidung und elektronische Datenverarbeigung. Methodenorientierte Vorstudie (La decisión jurídica y el tratamiento electrónico de datos. Estudio preliminar de orientación metodológica). Frankfurt: S. Tosche-Mittler Verlag (Athenäum).

KOLAKOWSKI, L. (1970). El racionalismo como ideología (trad. J. Muñoz). Barcelona: Ariel. [Además forma parte, en otra traducción, de: Kolakowski, 1993].

KOLAKOWSKI, L. (1975). La presencia del mito (trad. C. Piechocki). Buenos Aires: Amorrortu.

Kolakowski, L. (1993). Tratado sobre la mortalidad de la razón (trad. M. Mascialino). Caracas: Monte Avila.

Kopperschmidt, J. (1978 y 1980). Das Prinzip vernünftiger Rede (Sprache und Vernunft, Teil 1) + Argumentation (Sprache und Vernuinft Teil II) [El principio discurso racional, (Lenguaje y razón, Parte I) + Argumentación (Lenguaje y razón, Parte II)], Stuttgart-Berlin-KölnMainz: W. Kohlhammer.
Kraft, V. (1951). Die Grundlagen einer wissenschaftlichen Wertlehre (Los fundamentos de una teoría axiológica científica). Wien: Springer ( $2^{\text {a }}$ ed., reelab.).

Kraft, V. (1961). Rationale Moralbegründung (Fundamentación racional de la moral). Graz-Wien-Köln: Hermann Böhlaus Nachf.

Kriele, M. (1977). Theorie der Rechtsgewinnung, entwickelt am Problem der Verfassungsinterpretation (Teoría de la obtención del derecho, desarrollada en atención al problema de la interpretación constitucional) [esp. cap. 3 , «Die Topik als verfassungsjuristische Methode» (La tópica como método jurídico constitucional)]. Berlin: Duncker \& Humblot ( $2^{\text {a }}$ ed.).

Kutschera, F. (1973). Einführung in die Logik der Normen, Werte und Entscheidungen (Introducción a la lógica de las normas, valores y decisiones). FreiburgMünschen: Karl Alber.

Ladrière, J. (1978). El reto de la racionalidad (trad. J. M. González Holguera). Salamanca: Sígueme.

Lakatos, I. y Musgrave, A. (Eds.) (1975). La crítica y el desarrollo del conocimiento (trad. F. Hernán). Barcelona-Buenos Aires-México: Grijalbo.

Lalande, A. (1968). Vocabulaire technique et critique de la philosophie (entradas: «Raison», «Raisonnable», «Rationalité», «Rationnel»). Paris: Presses Universitaires de France (10 ed.). [Hay trad. al español (Buenos Aires, 1953, El Ateneo) de la 5 a ed. fr. (1947)].

Lorenzen, P. (1978). Theorie der technischen und politischen Vernunft (Teoría de la razón técnica y política). Stuttgart: Reclam.

Löwith, K. (1960). «Webers Interpretation der bürgerlich-kapitalistischen Welt am leitfaden der "Rationalisierung"» (La interpretación del mundo burgués-capitalista por Weber bajo el hilo conductor de la "racionalización"). En Gesammelte Abhandlungen. Zur Kritik der geschichtlichen Existenz (Compilación de 
estudios. Para la crítica de la existencia histórica), cap. I.II.A (pp. 8 y ss.). BerlinKöln-Mainz: V. Kohlhammer.

Lübbe, H. (1971). Theorie und Entscheidung. Studien zum Primat der praktischen Vernunft (Teoría y decisión. Estudios sobre el pruimado de la razón práctica) [esp. pp. 7-31 y 54-84]. Freiburg: Rombach.

Luhmann, N. (1973). Zweckbegriff und Systemrationalität (El concepto de finalidad y la racionalidad sistémica). Frankfurt: Suhrkamp. [Además ver: Habermas y Luhmann, 1971].

Lukács, G. (1976). El asalto a la razón. La trayectoria del irracionalismo desde Schelling hasta Hitler (trad. W. Roces) [esp.: Intr. y cap. VI.4 y Epíl.]. Barcelona: Grijalbo.

MACDONALD, M. (1951). «The Language of Political Theory», En A. G. Flew (Ed.), Essays on Logic and Language II, pp. 167-186. Oxford: Basil Blackwell.

Mannheim, K. (1969). «Elementos racionales e irracionales en nuestra sociedad», En El hombre y la sociedad en la época de crisis (trad. F. Ayala), pp. 21-64. Buenos Aires: La Pléyade.

Marcuse, H. (1969). El marxismo soviético (trad. Juan M. de la Vega), Madrid: Alianza Editorial.

Marcuse, H. (1971). Razón y revolución: Hegel y el surgimiento de la teoría social (trad. J. Fombona de Sucre y F. Rubio Llorente). Madrid: Alianza Editorial.

Marcuse, H. (1972). El hombre unidimensional. Ensayo sobre la ideología de la sociedad industrial avanzada (trad. A. Elorza) [esp. caps. 4-6]. Barcelona: Seix Barral.

Marí, E. E. (1986). «Racionalidad e imaginario social en el discurso del orden». Doxa, 3: 93-111.

Mosterín, J. (1978). Racionalidad y acción humana [esp. caps. 1-3]. Madrid: Alianza Editorial.

Muguerza, J. (1977). La razón sin esperanza, Madrid: Taurus.

NAESS, A. (1975). Kommunikation und Argumentation (Comunicación y argumentación). Kronberg/Ts.: Scriptor.
Nino, C. S. (1989). El constructivismo ético. Madrid: Centro de Estudios Constitucionales.

Newton-Smith, V. H. (1987). La racionalidad de la ciencia (trad. M. A. Galmarini). Barcelona: Paidós.

Olson, M. (1992). La lógica de la acción colectiva (trad. R. Calvet Pérez). México: Limusa.

Otte, G. (1970). «Zwanzig Jahre TopikDiskussion: Ertrag und Aufgaben» (Veinte años de discusión sobre la tópica: resultado y tareas). Rechtstheorie, 1(2): 183-197.

Paramio, L. (2000). «Decisión racional y acción colectiva». Leviatán, 79: 65-83.

Paramio, L. (2005). «Teorías de la decisión racional y de la acción colectiva». Sociológica, año 19, n 57: 13-34.

PARETO, V. (1980). Forma y equilibrio sociales. Extracto del Tratado de Sociología General (Selección e Intr. por G. Braga, trad. J. L. Pacheco) [esp. pp. 54-60]. Madrid: Alianza Editorial.

Parsons, T. (1968). La estructura de la acción social (trad. J. J. Caballero y J. Castillo Castillo). Madrid: Guadarrama.

Parsons, T. (1999). El sistema social (trad. J. Cazorla Pérez y J. Jiménez Blanco). Madrid: Alianza Editorial.

Perelman, C. (1963). Justice et raison. Paris: Presses Universitaires de France.

Perelman, C. (1979). La lógica jurídica y la nueva retórica (trad. L. Díez-Picazo). Madrid: Monografías Civitas. [Crítica: Haba, 1990 (Apéndice 2); y mucho más ampliamente, Haba, 2010c].

PERELMAN, C. y OLBRECHTS-TYTECA, L. (1989). Tratado de la Argumentación. La Nueva Retórica (trad. J. Sevilla Muñoz). Madrid: Gredos. [Estudio complementario: Gómez Giraldo, 2003].

Piacenza, E. (1998). Teoría de la argumentación. Lógica y no-monotonía. Maracaibo: Memorias del ciclo de conferencias «XXX Aniversario del Centro de Estudios Filosóficos "Adolfo García Díaz"».

Pizzorno, A. (1989). «Algún otro tipo de alteridad: una crítica a las teorías de la elección racional». Sistema, 88: 27-42. 
Poirier, R. (1978). «Rationalité juridique et rationalité scientifique». En Archives de Philosophie du Droit, 1978, 11-34.

POLANYI, M. (1962). Personal Knowledge. Towards a Post-Critical Philosophy. London: Routledge \& Kegan Paul.

Polya, G. (1966). Matemáticas y razonamiento plausible (trad. J. L. Abellán) [esp.: Prefacio, caps. I-II y xI-XIII]. Madrid: Tecnos.

Priester, J.-M. (1970). «Rationalität und funktionale Analyse» (Racionalidad $y$ análisis funcional). Jahrbuch für Rechtssoziologie und Rechtstheorie, I (Die Funktion des Rechts in der modernen Gesellschaft), 457-489. [Es un extracto, como adelanto, de Rationalität und Normkritik (Racionalidad y crítica de las normas): Tesis del autor en la Rechs- und wirtschaftswissenschaftlichen Fakultät der Universität des Saarlandes, Saarbrücken, 1972].

Rawls, J. (1979). Teoría de la Justicia (trad. M. D. González) [esp. caps. III y vII $+\S 87$ ]. México: Fondo de Cultura Económica [Análisis critico: Haba, 2009.]

Recaséns Siches, L. (1971). Experiencia juridica, naturaleza de la cosa y Lógica «razonable». México: PCE-unam.

Ricoeur, P. (2010). Écrits et conferences. Tome II: Herméneutique. Paris: Seuil.

ROBINSON, R. (1954). Definition. Oxford: Clarendon.

Röd, W. (1977). La filosofía dialéctica moderna (trad. J. J. Cruz). Pamplona: Universidad de Navarra.

Romano G. G. (2013). «Acerca de la condición normativa de la teoría de la decisión racional». Cuadernos de Economía ( Santafé de Bogotá ), vol. 32, no 60: 413-436.

ROTHER, W. (1972). Die Kunst des Streitens (El arte de la discusión). Münschen: Goldmans Gelbe Taschenbücher, 1966.

RUSSELL, B. (1967). Misticismo y lógica y otros ensayos (trad. J. Rovira Armengol) [esp. § 1]. Buenos Aires: Paidós.

Salas, M. E. (2004): «Vade Retro, Fortuna: O de la expulsión de Satanás - el Azardel mundo de las ciencias sociales (con especial énfasis en la Ciencia Jurídica)». Doxa, 27: 377-391.

Salas, M. E. (2011). Yo me engaño. tú te engañas, él se... Un repertorio de sofismas comunes en las ciencias sociales. San José (c.r.): Isolma.

SALAS, M. E. (2012). «Sin Derecho ni Razón. Sobre el garantismo penal de L Ferrajoli: su carencia de validez científica y de practicidad real». Doxa, 35: 751-789.

SALAS, M. E. (2017). «Teoría de la argumentación contra el argumentum porci», en Aguiló Regla, J y Grández Castro, P. (Eds.), Sobre el razonamiento judicial. Una discusión con Manuel Atienza, Lima: Palestra, 1977, 329-346.

Sarlo, Ó. (1994). «La teoría de la argumentación o nueva retórica de Perelman». En Instituto de Filosofía del Derecho, 1994, 99-109.

Sartre, J.-P. (1960). Critique de la raison dialectique (précédé de Questions de methode). tome I, Théorie des ensembles pratiques [esp. Introduction A: «Dialectique dogmatique et dialectique critique»]. Paris: Gallimard.

Scheffrin, S. M. (1985). Expectativas racionales. Madrid: Alianza Universidad.

Schlink, B. (1972). «Inwieweit sind juristische Entscheidungen mit entscheidungstheoretischen Modellen theoretisch zu erfasen und praktisch zu bewältigen?» (¿Hasta dónde es dable que, mediante modelos teoréticos de decisión, las decisiones jurídicas sean susceptibles de aprehenderlas teoréticamente $y$ de dominarlas en la práctica?). Jahrbuch für Rechtssoziologie und Rechtstheorie, 2 (Rechtstheorie als Grundlagenwissenschaft der Rechtswissenschaf): 322-346.

SCHOPENHAUER, A. (2005). El arte de tener razón, expuesto en 38 estratagemas. Dialéctica erística (Comentario y trad. D. Garzón). Madrid: Biblioteca Edaf.

Schrey, H.-H. (1970). Dialogisches Denken (Pensamiento dialógico). Darmstadt: Wissenschaftliche Buchgesellschaft.

SCHUTZ, A. (1974), «El problema de la racionalidad en el mundo social». En Brodersen, 
A. (Comp.), Estudios de teoría social (trad. N. Míguez, rev. A. Bignani), cap. 3. Buenos Aires: Amorrortu.

Simon, H. A. 1989. Naturaleza y Límites de la Razón Humana (trad. E. G. Tapia). México: Fondo de Cultura Económica.

Simon-Schaefer, R. (1973). Dialektik. Kritik eines Wortgebrauchs (Dialéctica. Crítica de un uso lingüístico). Stuttgart-Bad Cannstaat: problemata fromann-holzbog 24.

SOKAL, A. y BRICMONT, J. (1999). Imposturas intelectuales, (trad. J. C. Guix Vilaplana, rev. técn. Miguel Candel). Barcelona: Paidós. [Complemento: Bouveresse, 2001].

Stegmüller W. (1973). Probleme und Resultate der wissenschaftstheorie und analytischen Philosophie (Problemas y resultados de la teoría de la ciencia y de la filosofía analítica), vol. Iv(1), Personelle und statistische Wahrscheinlichkeit (Probabilidad personal y estadística), 1. Halbband, Personnelle Wahrscheinlischkeit und rationale Entscheidung (Probabilidad personal y decisión racional) [esp. Parte I, secs. 1-6]. Berlin-Heidelberg-New York: Springer.

STEGMÜLLER, W. (1975). Der sogenannte Zirkel des Verstehens (El, así llamado, círculo del comprender). En Id., Das Problem der Induktion: Humes Herausforderung und moderne Antworten (El problema de la inducción: el desafío de Hume y respuestas modernas). Darmstadt: Wissenschaftliche Buchgesellschaft.

STEVENSON, C. L. (1971). Ética y lenguaje, (trad. E. A. Rabosi). Buenos Aires: Paidós.

STRASSER, C. (1977). La razón científica en política y sociología. Buenos Aires: Amorrortu.

Struck, G. (1971). Topische Jurisprudenz, Argument und Gemeinplatz in der juristischen Arbeit (Jurisprudencia tópica. Argumento y lugar común en el trabajo jurídico). Frankfurt: Athenäum.

Struck, G. (1977). Zur Theorie juristischer Argumentation (Sobre la teoría de la argumentación jurídica). Berlin: Duncker \& Humblot.
Tenbruck, F. (1972). Zur Kritik der planenden Vernunft (Para la crítica de la razón planificadora). Freiburg-Münschen: Karl Alber.

Tiercelin, C. (2014). La reconstruction de la raison. Dialogues avec Jacques Bouveresse. Paris: Collège de France.

Topitsch, E. (Ed.) (1965). Logik der Sozialwissenschaften (Lógica de las ciencias sociales). Köln: Kiepenheuer \& Witsch.

Topitsch, E. (1971). Sozialphilosophie zwischen Ideologie und Wissenschaft (Filosofía social, entre ideología y ciencia). Neuwied am Rhein-Berlin: Luchterhand.

TOPITSCH, E. (1988). Erkenntnis und Illusion. Grundstrukturen unserer Weltauffassung (Conocimiento e ilusión. Estructuras fundamentales de nuestra manera concebir el mundo). Tübingen: J. C. B. Mohr (Paul Siebeck) (2a ed.).

Toulmin, S. (1958). The Uses of Argument [esp. Secs. A y C]. London: Cambridge University Press. [Crítica: Haba, 2010c (§ I.2 (esp. p. 330 y ss.); o en Haba, 2014 (p. 42 y ss.); véase. también Atienza y Jiménez Redondo, 1993].

Toulmin, S. (1977). La comprensión humana 1: El uso colectivo y la evolución de los conceptos (trad. N. Míguez). Madrid: Alianza Universidad.

Toulmin, S. (1979) El puesto de la razón en la ética (trad. I. F. Ariza). Madrid: Alianza Universidad.

VAZ FERREIRA, C. (1963). Lógica viva (Adaptación práctica y didáctica). Montevideo: Homenaje de la Cámara de Representantes de la República Oriental del Uruguay, vol. iv. [Comentario: E. P. Haba, «Lógica viva (Vaz Ferreira) como base de pensamiento para contraponer a la hegemonía del "geometrismo" en la actual Teoría del Derecho», en I Congreso de Filosofía del Derecho para el Mundo Latino, Alicante, 26-28 de mayo de 2016 (http://iusfilosofiamundolatino.ua.es/)].

Viehweg, T. (1987). Tópica y jurisprudencia (Pról. E. García de Enterría, trad. L. Díez Picasso), Madrid: Taurus. 
Villey, M., 1976. «Sur la dialectique comme art du dialogue». Archives de Philosophie du Droit, 21 (Genèse et declin de l'État): 215-227. [Comentario: Castro Rivera y Meliante Garcé, 1993].

WAISMANN, F. (1951). «Verifiability». En A. G. Flew (Ed.), Essays on Logic and Language, First Series, pp. 117-144. Oxford: Basic Blackwell.

WALLAS, G., 1962. Human Nature in Politics, (Intr. A. L. Rowse). Lincoln (usA): University of Nebraska Press.

Weber, M. (1964). «Conceptos sociológicos fundamentales». En Id., Economía y sociedad, t. I (Prmera Parte, § I.1.I: pp. 5 y ss.). México: Fondo de Cultura Económica.

WEBER, M. (1973). Ensayos sobre metodología sociológica (Intr. P. Rossi, trad. J. L. Etcheberry). Buenos Aires: Amorrortu.

WELDON, T. D. (1953). The Vocabulary of Politics. London: Penguin Books.

Wilson, B. R. (Ed.) (1970). Rationality. Oxford: Basil Blackwell.

Whitehead, A. N. (1985). La función de la razón (Intr., trad. y notas: L. González Pasos). Madrid: Tecnos.

Fecha de ingreso: 29/11/2017 Fecha de aprobación: 22/03/2018 
